\title{
Neuronal Activities in Brain-Stem Cholinergic Nuclei Related to Tonic Activation Processes in Thalamocortical Systems
}

\author{
M. Steriade, S. Datta, D. Paré, G. Oakson, and R. Curró Dossi \\ Laboratoire de Neurophysiologie, Faculté de Médecine, Université Laval, Québec, Canada G1K 7P4
}

This study was performed to examine the hypothesis that thalamic-projecting neurons of mesopontine cholinergic nuclei display activity patterns that are compatible with their role in inducing and maintaining activation processes in thalamocortical systems during the states of waking (W) and rapid-eye-movement (REM) sleep associated with desynchronization of the electroencephalogram (EEG). A sample of 780 neurons located in the peribrachial (PB) area of the pedunculopontine tegmental nucleus and in the laterodorsal tegmental (LDT) nucleus were recorded extracellularly in unanesthetized, chronically implanted cats. Of those neurons, 82 were antidromically invaded from medial, intralaminar, and lateral thalamic nuclei; $\mathbf{5 7 0}$ were orthodromically driven at short latencies from various thalamic sites; and 45 of the latter elements are also part of the 82 cell group, as they were activated both antidromically and synaptically from the thalamus.

There were no statistically significant differences between firing rates in the PB and LDT neuronal samples. Rate analyses in 2 distinct groups of PB/LDT neurons, with fast ( $>10$ $\mathrm{Hz}$ ) and slow $(<2 \mathrm{~Hz})$ discharge rates in $W$, indicated that (1) the fast-discharging cell group had higher firing rates in $W$ and REM sleep compared to EEG-synchronized sleep (S), the differences between all states being significant $(p<$ $0.0005)$; (2) the slow-discharging cell group increased firing rates from $W$ to $S$ and further to REM sleep, with significant difference between $W$ and $S(p<0.01)$, as well as between $W$ or $S$ and REM sleep ( $p<0.0005)$.

Interspike interval histograms of PB and LDT neurons showed that $75 \%$ of them have tonic firing patterns, with virtually no high-frequency spike bursts in any state of the wake-sleep cycle. We found 22 PB cells that discharged rhythmic spike trains with recurring periods of $0.8-1 \mathrm{sec}$. Autocorrelograms revealed that this oscillatory behavior disappeared when their firing rate increased during REM sleep.

Dynamic analyses of sequential firing rates throughout the waking-sleep cycle showed that none of the full-blown states of vigilance is associated with a uniform level of spontaneous firing rate. Signs of decreased discharge frequencies of mesopontine neurons appeared toward the end of quiet

\footnotetext{
Received Dec. 14, 1989; revised Feb. 16, 1990; accepted Mar. 12, 1990.

This work was supported by the Medical Research Council of Canada (MT3689). S.D. was a postdoctoral fellow, on leave of absence from All-India Institute of Medical Sciences, New Delhi, India. D.P. had an MRC studentship. R.C.D. was a postdoctoral fellow, on leave of absence from University of Padova, Italy. We thank P. Giguère and D. Drolet for skillful technical assistance.

Copyright (C) 1990 Society for Neuroscience 0270-6474/90/082541-19\$03.00/0
}

$W$, preceding by about $10-20$ sec the most precocious signs of EEG synchronization heralding the sleep onset. During transition from $S$ to $W$, rates of spontaneous discharges increased 20 sec before the onset of EEG desynchronization. Similarly, a group analysis of PB/LDT cells showed precursor changes of increased discharge rates during transition from $\mathrm{S}$ to $\mathrm{REM}$ sleep, $1 \mathrm{~min}$ in advance of EEG desynchronization $(p<0.05)$.

The enhanced level of spontaneous discharge during $W$ and REM sleep was paralleled by an increase in neuronal excitability. Indeed, the probability of antidromic responses increased by $30-80 \%$ during REM sleep, and the probability of synaptically evoked discharges increased by $40-85 \%$ from $S$ to either $W$ or REM sleep.

We conclude that neurons in thalamic-projecting mesopontine cholinergic nuclei are good candidates for preparing and maintaining the tonic activation processes in thalamocortical systems during $W$ and REM sleep associated with EEG desynchronization. In our view, this action is accomplished by direct depolarization of thalamocortical neurons and by the inhibition of the thalamic generator of synchronized spindle oscillations.

On the basis of transection cxpcriments showing that a midpontine pretrigeminal cat is fully aroused, whereas a cut only 4-5 mm more rostral induces uninterrupted sleep, Moruzzi (1972) concluded that "the neurons lying between the 2 sections are the likely candidates for explaining the critical differences in both the EEG and ocular behavior" (p. 31). It is precisely in that region, at the mesopontine junction, that 2 cholinergic cell aggregates were later disclosed: the pedunculopontine tegmental (PPT) and laterodorsal tegmental (LDT) nuclei, or Ch5 and Ch6 groups (Mesulam et al., 1983; Vincent and Reiner, 1987).

The long-standing hypothesis of a brain-stem cholinergic system relayed by thalamic nuclei with cortical projections was recently confirmed by combining retrograde transport techniques with choline acetyltransferase (ChAT) immunohistochemistry in the cat (Paré et al., 1988; Smith et al., 1988; Steriade ct al., 1988) and rat (Woolf and Butcher, 1986; Hallanger et al., 1987). It is now known that stimulation of brain-stem cholinergic nuclei induces tonic and phasic depolarizing effects upon thalamocortical neurons which are compatible with the notion of an ascending activating system operating during both EEG-desynchronized behavioral states of waking (W) and rapideye-movement (REM) sleep (see Discussion). The basal forebrain neurons provide an important contingent for the cholinergic activation of the cerebral cortex (Buzsaki et al., 1988), but 
the overwhelming majority of their brain-stem inputs arise in noncholinergic neurons (Jones and Cuello, 1989) and the functional sign of this circuit is not yet elucidated.

In this and the following paper (Steriade et al., 1990b), we examine the activities of neurons recorded from the peribrachial (PB) area of the PPT nucleus and from the LDT nucleus during the waking-sleep cycle to evaluate their role in cardinal activation processes in thalamocortical systems, namely, tonic EEG desynchronization and phasic ponto-geniculo-occipital (PGO) waves.

The present study deals with the enduring process of EEG desynchronization, characterizing both brain-activated states of $\mathrm{W}$ and REM sleep. To play a role in inducing and maintaining EEG desynchronization, PB and LDT neurons should fulfill several criteria. (1) They should have identified projections to the thalamus; (2) their discharge rates should change in advance of the shifts between states of vigilance, when most dramatic neuronal changes are expected to occur; and (3) the analysis of changes in background discharges should be completed by tests of cell excitability. Thalamic and cortical recordings indeed showed that an enhanced probability of cellular responsiveness may appear during periods of arousal associated with decreased spontaneous firing (Steriade et al., 1974; Livingstone and Hubel, 1981). We have therefore investigated the responses of $P B$ and LDT cells to antidromic and orthodromic volleys during waking and sleep states.

These analyses led us to conclude that PB and LDT neurons are among the best candidate substrates to account for the tonic activation processes in thalamocortical neurons. The thalamic arousal is reflected upon cortical neurons in concert with the direct cholinergic actions of basal forebrain neurons as well as brain-stem and posterior hypothalamic monoaminergic systems.

\section{Materials and Methods}

Preparation. Chronic experiments were conducted on 9 adult cats. The implantation procedures were performed under sodium pentobarbital anesthesia $(35 \mathrm{mg} / \mathrm{kg})$. First, the tentorium was removed in order to make possible the insertion of recording microelectrodes in a perpendicular direction with respect to the horizontal plane. This permitted more accurate penetrations within the mesopontine nuclei, according to conventional stereotaxic coordinates. Recording leads for monitoring the behavioral state of vigilance consisted of stainless steel screws into the calvarium overlying the suprasylvian gyrus (for EEG rhythms), silver-ball electrodes cemented into the supraorbital cavity (for eye movements, EOG), Teflon-isolated wires into neck muscles (for electromyogram, EMG), and coaxial electrodes into the lateral geniculate nucleus (for thalamic PGO waves). The thalamic stimulating electrodes are described below. Cats were implanted in a stereotaxic position in order to keep the head rigidly held, without pain or pressure (Steriade and Glenn, 1982). Recordings began 7-10 d after surgery. Animals slept ad libitum between recording sessions.

Recording. During recording, the head was restrained, but the animals could move their limbs freely and often made postural adjustments. Neuronal discharges (signal-to-noise $>5: 1$ ) were recorded with tungsten microelectrodes (1-2 $\mu \mathrm{m}$ tip diameter, 2-8 $\mathrm{M} \Omega$ at $1 \mathrm{kHz}$ ). Presumed fibers, with very short duration $(<0.8 \mathrm{msec})$ and exclusively positive action potentials, were not analyzed. Unitary spikes and focal waves were recorded simultaneously on direct $(50-10,000 \mathrm{~Hz})$ and FM (1$700 \mathrm{~Hz}$ ) channels of a tape recorder, along with trigger pulses and signals of physiological variables used to distinguish behavioral states (EEG, EOG, EMG, and thalamic PGO waves).

Stimulation. The stimulating electrodes consisted of 6 tungsten microelectrodes (1-1.5 mm apart) or 4 coaxial electrodes ( $2 \mathrm{~mm}$ apart) inserted into the medial, intralaminar, and lateral thalamic nuclei. We reached in different preparations the anteromedial, anteroventral, me- diodorsal and ventromedial nuclei, rostral intralaminar (centrolateralparacentral), ventroanterior-ventrolateral, lateroposterior-pulvinar, lateral geniculate, and reticular thalamic complexes. However, we cannot ascertain that terminal fibers were stimulated to inducc antidromic invasion of brain-stem neurons. Therefore, more conservative terms (medial, intermediate, and lateral thalamic nuclei) are generally used to describe the projections of the recorded elements. We succeeded in modifying the antidromic or orthodromic type of responses by changing the stimulus polarity and location (see Fig. 4). When studying cell responsiveness to antidromic and/or orthodromic volleys, stimulus intensity was adjusted to evoke discharges in approximately $40-70 \%$ of the trials to avoid saturation effects. Stimulation intensities were kept below the threshold for overt movements. There was no behavioral sign that the electrical stimulation was experienced or that the sleep cycle was disturbed.

Histology. After the completion of recording sessions, the animals were deeply anesthetized with sodium pentobarbital $(45-50 \mathrm{mg} / \mathrm{kg})$ and pcrfused with 0.5 liter of $0.9 \%$ saline followed by 1 litcr of $4 \%$ paraformaldehyde. The locations of stimulating thalamic electrodes were verified on $80 \mu \mathrm{m}$ frontal sections stained with thionine. The locations of brain-stem recording microelectrodes were verified on $80 \mu \mathrm{m}$ frontal sections stained with NADPH-diaphorase, a reliable marker of brainstem cholinergic neurons (Vincent et al., 1983), and counterstained with neutral red (Fig. 1). Small electrolytic lesions $(0.03-0.15 \mathrm{~mA}$ for $10 \mathrm{sec})$ were made along successful microelectrode tracks (bottom arrow in Fig. $1 A$ ). The cells were located by combining the histological controls and micrometer readings. Neurons found outside the PB/LDT neurons were not included in analyses. Although some studies emphasized that cholinergic neurons recorded from a series of central structures are characterized by their long-duration action potentials, we did not rely on this criterion which is questionable in an extracellular position. Presumptive mesopontine cholinergic cells are termed in this paper those elements that have been recorded within PB/LDT histological limits, as determined by means of NADPH-diaphorase staining (Fig. 1).

Analyses of discharge rates and patterns during full-blown states and transitional epochs of the waking-sleep cycle. We analyzed 3 full-blown states (waking, W; sleep with EEG synchronization, S; and REM sleep) and 2 transitional epochs (WS and pre-REM; Fig. 2). The physiological correlates of the so-called steady states are well known (see Steriade and Hobson, 1976). The time 0 of the transitional epoch from W to S (WS) was marked by the appearance of the first spindle sequences on the background of EEG desynchronization. The WS epoch was characterized by repeated synchronizing-desynchronizing shifts in EEG activity, associated with closing and reopening the eyes, and its duration varied considerably $(10 \mathrm{sec}-2 \mathrm{~min})$. The onset of $\mathrm{S}$ state was defined as the time when the EEG synchronization was no longer interrupted by transient periods of desynchronization. Time 0 of the transitional state from $S$ to REM sleep (pre-REM) was taken as the occurrence of the first thalamic PGO wave. The onset of REM sleep was defined as the beginning of EEG desynchronization. Arousal from $S$ was associated with EEG desynchronization (followed by increased muscular tone and eye movements), while arousal from REM sleep was indicated by the reappearance of muscular tone which was preceded by the cessation of PGO waves and ocular saccades (Fig. 2). Firing rates and patterns during $W$ were analyzed from periods without gross movements or with only occasional, isolated eye movements. Thus, the measures reflect the state of quiet W.

Interspike intervals were measured to a resolution of $100 \mu \mathrm{sec}$ and stored in a computer. Vigilance states of W, WS, S, pre-REM, and REM were identified. For each cell epoch, the firing rates during the available states were calculated and tabulated. Identical states in all epochs of a cell were combined to give a weighted average firing rate for the state and cell.

Cells having rate data for specified sets of vigilance states (such as $\mathrm{W}$, $S$, and REM) were fetched and the medians and equally weighted mean rates for each state were computed for all cells along with the standard errors. The statistical significance of rate differences between pairs of states were calculated using the Wilcoxon paired-rank test.

Spike interval data were also used to compute individual interspike interval histograms (ISIHs) and pooled ISIHs for multiple cells using bin-by-bin medians. The autocorrelogram for oscillatory activity and the cross-correlogram between pairs of simultaneously recorded cells were also computed.

Sequential mean firing rates (SMFs) in 1 -sec bins were computed for state transitions from $W$ to $W S$ and $S, S$ to $W$, and $S$ to pre-REM and 

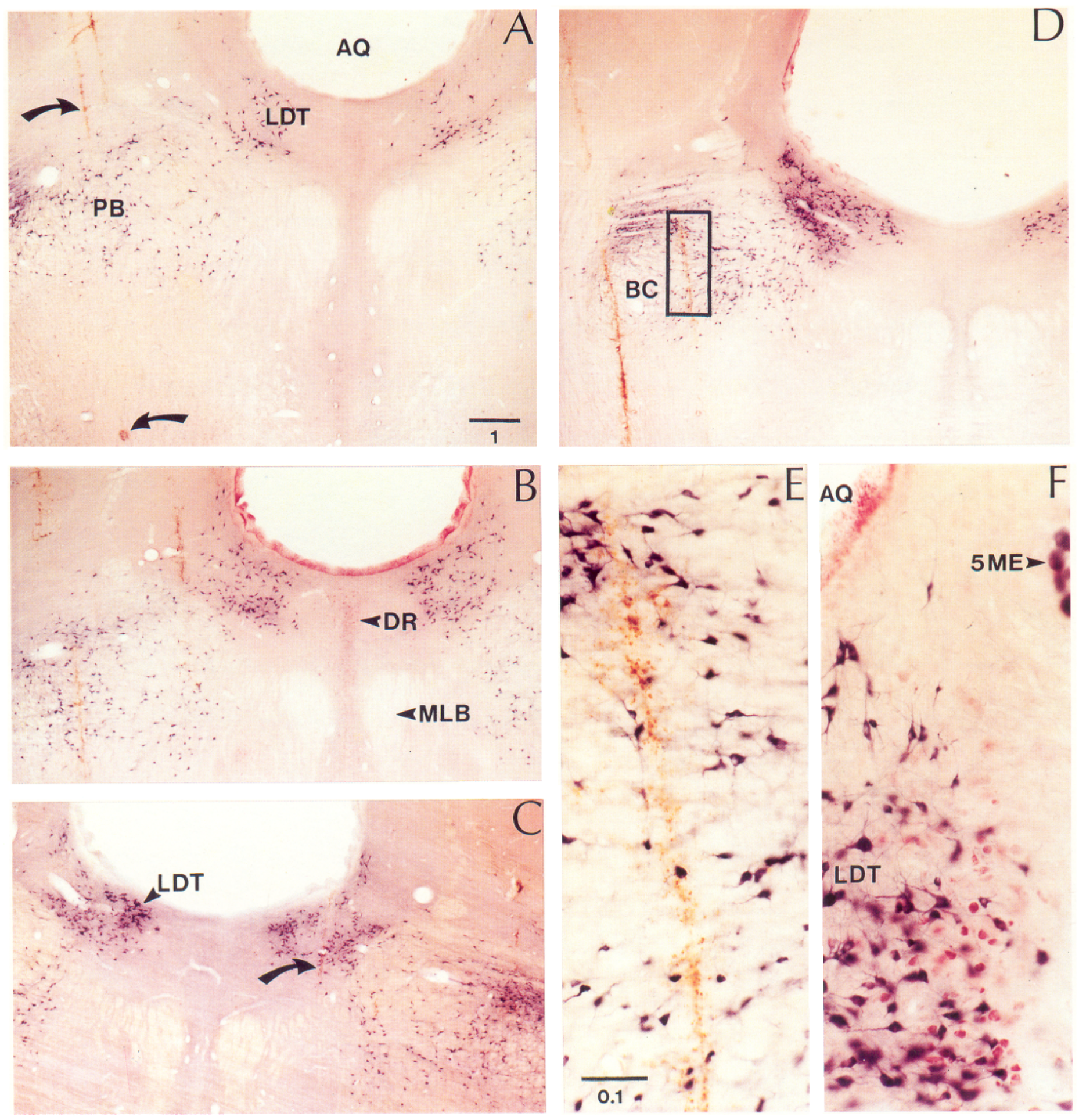

Figure 1. Histological localization of microelectrode tracks. Frontal sections stained for NADPH-diaphorase activity and counterstained with Neutral red. Sections $A-D$ are rostral to caudal, between frontal planes 0 and -1.5 . The rectangle in $D$ is depicted at higher magnification in $E$. Panel $F$ shows the cholinergic neurons in the LDT nucleus and the adjacent noncholinergic neurons (stained in red) in the locus coeruleus. Microelectrode tracks through the PB area and LDT nucleus are marked with arrows in $A$ and $C$. A small electrolytic lesion (bottom arrow in $A$ ) was made a few millimeters ventral to the last recorded neuron on that track. Horizontal bars indicate millimeters (bar in $A$ is valid for other panels, with the exception of $E$ and $F$ ). Abbreviations other than PB and LDT: $A Q$, aqueduct; $B C$, brachium conjunctivum; $D R$, dorsal raphe; $M L B$, medial longitudinal bundle; $5 M E$, mesencephalic nucleus of the 5 th nerve.

REM. For the 21 cells that had suitably long periods in S, pre-REM, and REM, pooled SMFs in 5 -sec bins were produced by aligning the SMFs from individual cells to the start of either the pre-REM or REM state and then calculating the bin-by-bin median rate across all cells for the time available. To gain some appreciation of the statistical signifi- cance of pooled SMF rate changes, the median rate for the first $30 \mathrm{sec}$ ( 6 bins) of the analyzed period was calculated for each of the 21 cells. These values were then successively paired on a bin-by-bin basis with the following bins of the epoch, and the Wilcoxon paired-rank test was computed on the rate changes of each bin-pair across all cells. 


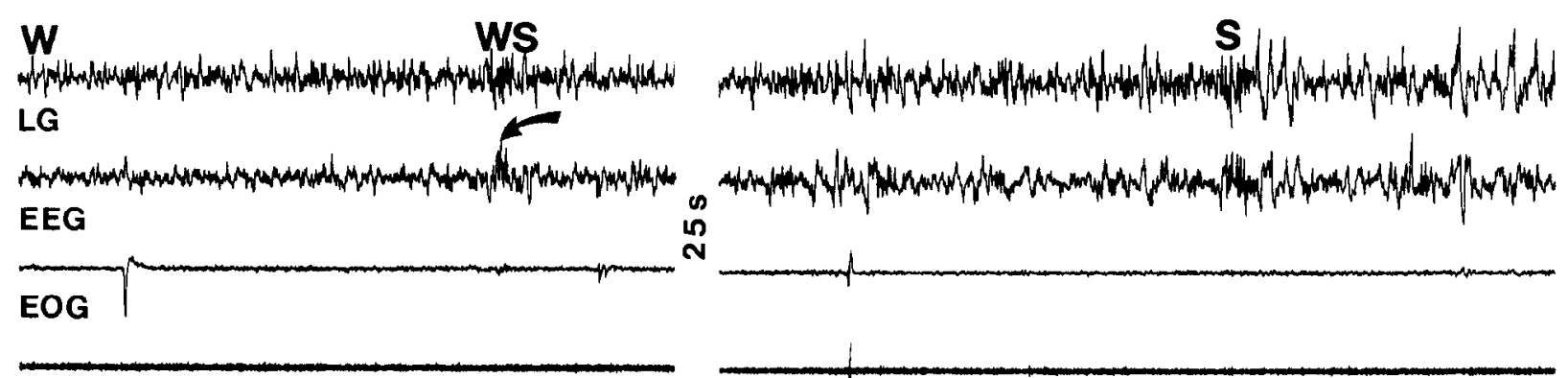

EMG
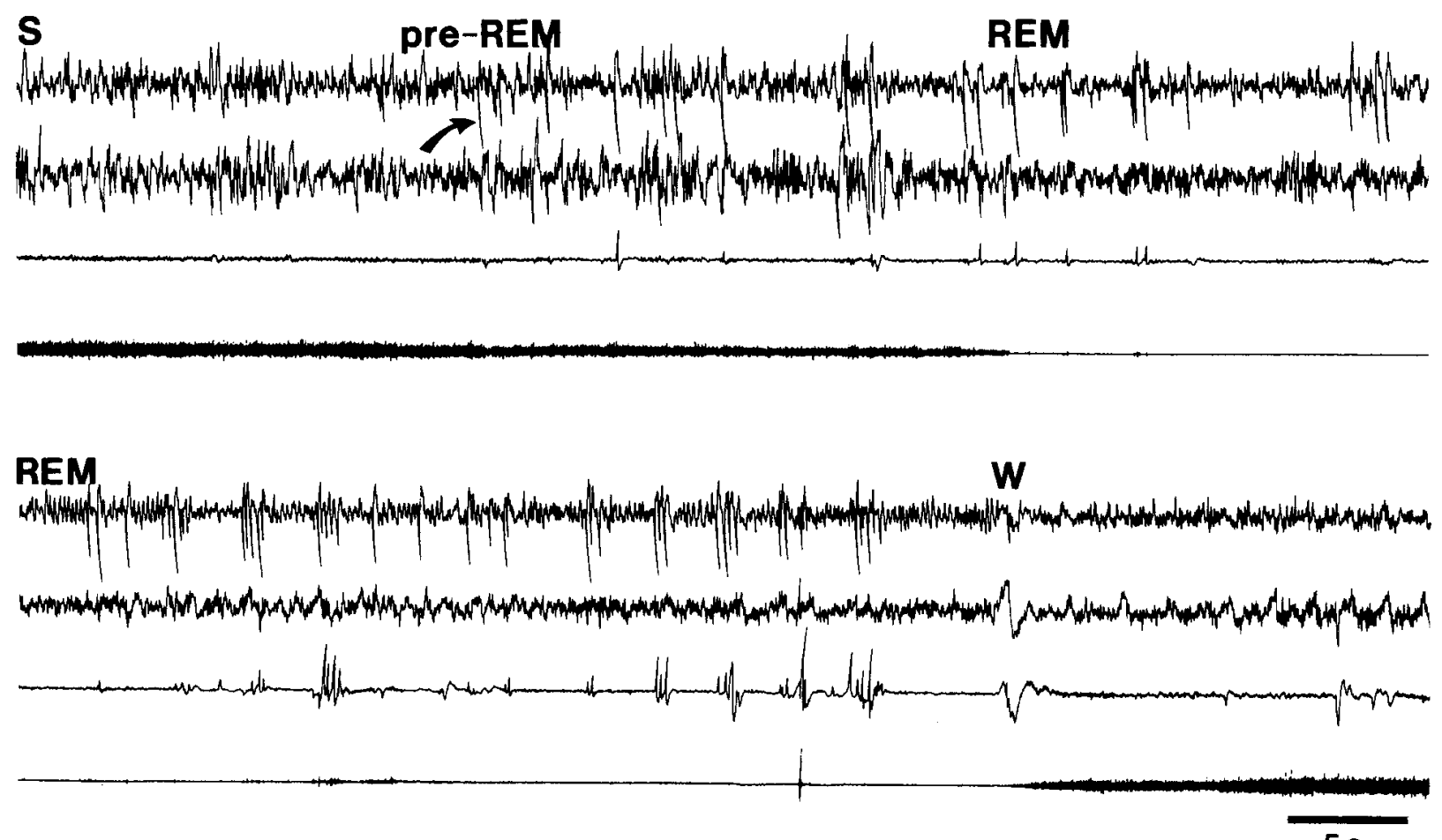

Figure 2. Criteria for distinguishing full-blown states and transitional epochs of the waking-sleep cycle. The 4 ink-written traces depict the activity of lateral geniculate $(L G)$ thalamic nucleus, EEG rhythms, ocular movements $(E O G)$, and activity of neck muscles $(E M G)$. W, waking; $S$, EEGsynchronized sleep; WS, transitional epoch between W and $\mathrm{S}$ beginning with the first spindle sequence (arrow; 25 sec elapsed between the 2 portions of WS leading to S); pre-REM, transitional epoch between S and REM sleep beginning with the first thalamic PGO wave (arrow).

\section{Results}

\section{Data base and neuronal identification}

We have recorded 780 cells within the histological limits of the rostral two-thirds of the PPT nucleus and in the LDT nucleus, as determined by their cholinergic neurons stained with the NADPH-diaphorase technique (Fig. 1). Our exploration of the PPT nucleus was thus limited to the PB area (Fig. 1, $A-D$ ) and did not include the more posterior parabrachial nucleus, aligned lateral to the most caudal portion of the brachium conjunctivum. The distinction between the PB and parabrachial sectors is important in view of the marked differences in the proportions of cholinergic and aminergic cells at these 2 levels (see Discussion). As shown below, there were no statistically significant differences between PB and LDT cells as far as firing rates and patterns during waking-sleep states are concerned. Therefore, in many instances we will use the global terms PB/LDT neurons or neurons of mesopontine cholinergic nuclei, unless we refer to a particular neuron or cell class.
Of those 780 cells, 82 were antidromically invaded from thalamic nuclei. Criteria for antidromic identification were fixed response latency, collision with spontaneously occurring spikes at proper intervals, and the ability to follow 2-3 stimuli at 250$300 \mathrm{~Hz}$ (see Figs. $3 A$, 4). Twelve neurons were backfired at different latencies from 2 distant nuclei (Fig. $3 A$ ).

The percentage of antidromically activated neurons from the total population of $\mathrm{PB} / \mathrm{LDT}$ tested elements (about 10\%) obviously does not reflect the dense innervation of thalamic nuclei from brain-stem cholinergic nuclei which provide $50-85 \%$ of the total afferents originating in the upper brain-stem reticular core of cat (Paré et al., 1988; Steriade et al., 1988). Low percentages of antidromically identified neurons are commonly reported in the literature. One explanation is that antidromic invasion may be blocked by hyperpolarization at the time of testing. Another factor accounting for the relatively low percentages of antidromically identified cells is that testing stimulation is usually applied to a quite limited number of structures. Indeed, we were concerned with brain-stem cholinergic actions on thala- 


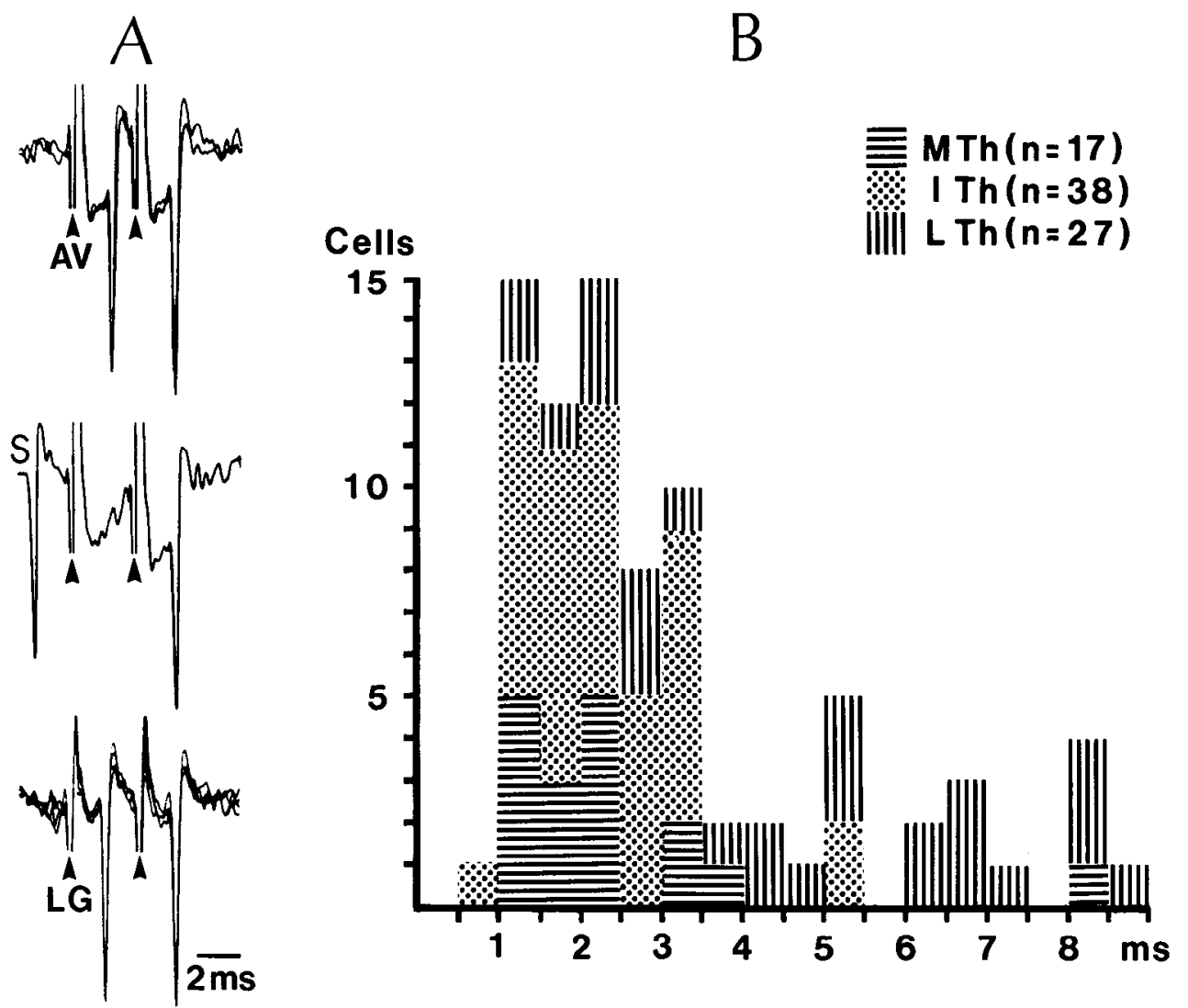

Figure 3. Antidromic identification of PB and LDT cells with thalamic projections. $A$, Fast-conducting LDT neuron, antidromically invaded from me$\operatorname{dial}(A V, 1.7-\mathrm{msec}$ response latency) and lateral $(L G, 1.4-\mathrm{msec}$ response latency) thalamic electrodes. Two stimuli (arrowheads) at $300 \mathrm{~Hz}$. Middle row; collision of the first antidromic spike with a spontaneous $(S)$ action potential. $B$, Histogram of antidromic response latencies in 82 PB and LDT cells. Symbols indicate loci where the tips of stimulating thalamic electrodes were located: $M T h$, medial nuclei: anteromedial, anteroventral, mediodorsal and ventromedial; $I T h$, intermediate thalamic region: intralaminar centrolateral-paracentral complex and medial parts of the lateroposterior and ventrolateral nuclei; and $L T h$, lateral nuclei: reticular, ventroanterior, pulvinar, lateral geniculate complex. When the same cell was antidromically invaded from 2 loci, the shortest latency response was included in the histogram. Note that responses with long latencies ( $>5 \mathrm{msec}$ ) were mostly evoked from LTh (reticular and lateral geniculate nuclei). In this and other figures, positivity upwards. mocortical systems and did not stimulate the ventrolateral posterior hypothalamus, whence antidromic activation of mesopontine tegmental neurons can also be elicited; however, only $5-10 \%$ of cells in this hypothalamic-projecting contingent are cholinergic (El Mansari et al., 1989). Yet another explanation of the low percentages of antidromic responses is that systematic modifications in the parameters and/or polarity of stimuli are seldom attempted in all cells. That subtle changes in stimulus polarity and location can significantly alter the cellular responsiveness is shown in Figure 4 illustrating 2 simultaneously recorded PB neurons. The synaptically evoked burst of neuron $a$ was transformed into an antidromic response by changing the polarity of stimulation applied between 2 microelectrodes inserted within the lateroposterior nucleus. Both neurons $a$ and $b$ were found to be antidromically activated (with different latencies) from the lateroposterior nucleus, but stimulation of the adjacent lateral geniculate nucleus induced an orthodromic response in both cells, probably by activating the descending pathway from the ventral part of the lateral geniculate complex (see Discussion). The temporal sequence of evoked synaptic discharges in the 2 cells (with $b$ preceding $a$ ) was corroborated by the same succession in cross-correlograms during W and $\mathrm{S}$ states (Fig. 4).

A much larger population of PB/LDT cells $(n=570)$ was synaptically driven at short latencies $(3-8 \mathrm{msec})$ from the thalamus. Twenty-five PB/LDT neurons responded with a burst of synaptically evoked discharges a few milliseconds after their antidromic invasion. In some of those cases, the state-dependent changes in probability of both antidromic and synaptic activities could be studied during the waking-sleep cycle (see Figs. 14, $15 A)$.
Out of $780 \mathrm{~PB} / \mathrm{LDT}$ cells, $585(75 \%)$ neurons discharged tonically. Such a pattern endows PB/LDT cells with properties qualifying them for the induction and maintenance of the tonic process of EEG desynchronization during $\mathrm{W}$ and REM sleep. The tonicity of discharges was first evaluated from the visual inspection of recordings showing single spikes, relatively evenly spread over time, during all states of vigilance. It was later confirmed by ISIHs in individual PB $(n=92)$ and LDT $(n=$ 27) cells, and in a pooled ISIH of $34 \mathrm{~PB} / \mathrm{LDT}$ cells with identified thalamic projections.

SMFs throughout the waking-sleep cycle or during at least 2 states with opposing. EEG patterns were analyzed in 138 neurons. Of them, 33 formed the basis for grouped analyses in neuronal pools during transitions between EEG-synchronized and EEG-desynchronized states. The relatively small neuronal samples analyzed for the transitions from W-to-WS-to-S $(n=$ 5), S-to-preREM-to-REM $(n=21)$, and S-to-W $(n=7)$, are accounted for by a series of factors: (1) most cells recorded throughout the cycle in the order S-REM-W were lost during gross movements in W, and the W-WS-S transition was thus lacking; (2) we needed at least $60-100 \mathrm{sec}$ for a reference period preceding time 0 of the subsequent transitional epoch or fullblown state; a purely quiet $\mathrm{W}$ state, with full EEG desynchronization and without movements, rarely lasts for such long periods in head-restrained animals; and (3) REM sleep may occur without a sufficiently long pre-REM period. Data qualitatively similar to those illustrated in our pooled analyses were observed in the remaining cells.

Peristimulus histograms (PSHs) of antidromic and orthodromic responses to thalamic stimuli were performed in $25 \mathrm{~PB} /$ LDT cells during all or at least 2 states of vigilance. 


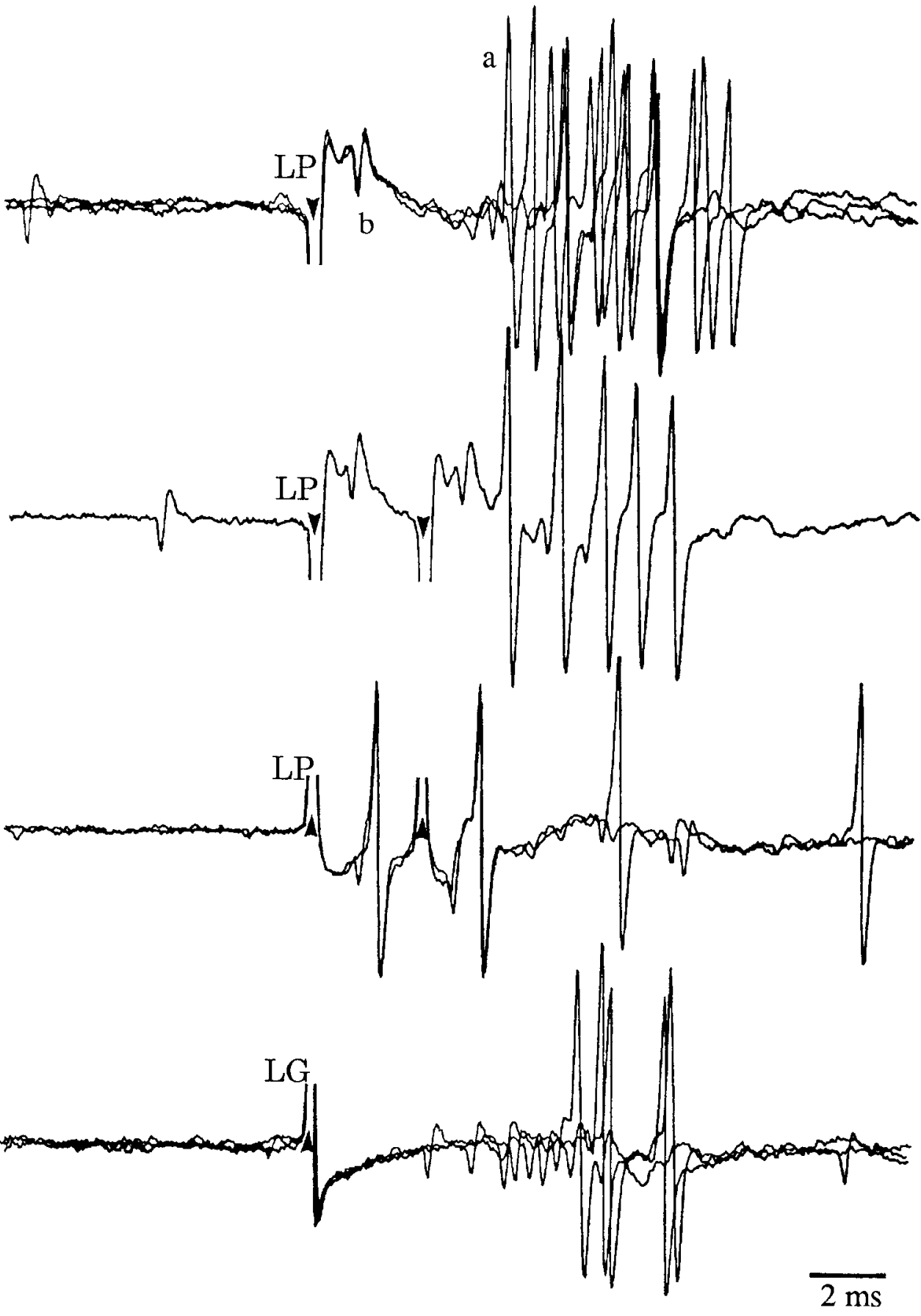

Figure 4. Changing features of neuronal identification by modifying stimulus polarity and location. Two simultaneously recorded neurons in the dorsomedial part of the PB area (large initially positive spike $a$ and small spike b). Two top traces: antidromic activation of neuron $b(1.3-\mathrm{msec}$ response latency) and synaptically evoked burst in neuron $a$ (about $5 \mathrm{msec}$ latency) by stimulating the lateroposterior $(L P)$ nucleus. Third trace: antidromic invasion of neuron a (1.6-msec latency) by changing the polarity of LP stimulus. Fourth trace: synaptic activation of both cells (shorter response latency in cell $b$ ) by stimulating the lateral geniculate $(L G)$ nucleus. Bottom: cross-correlograms of the 2 neurons (cell $a$ is the reference cell) during $\mathrm{W}$ and $\mathrm{S}$ states.
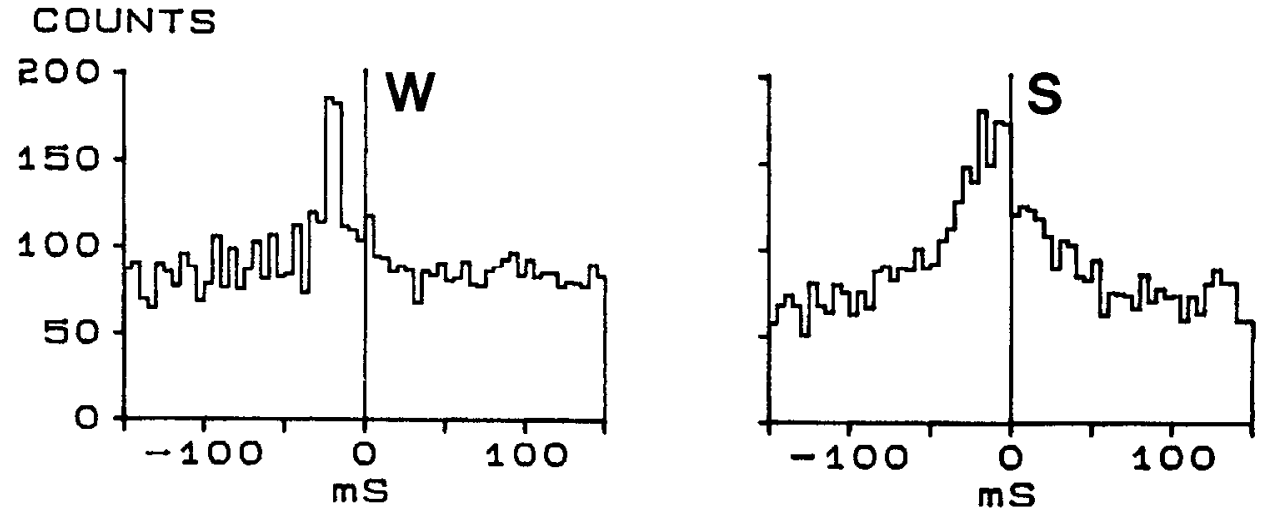

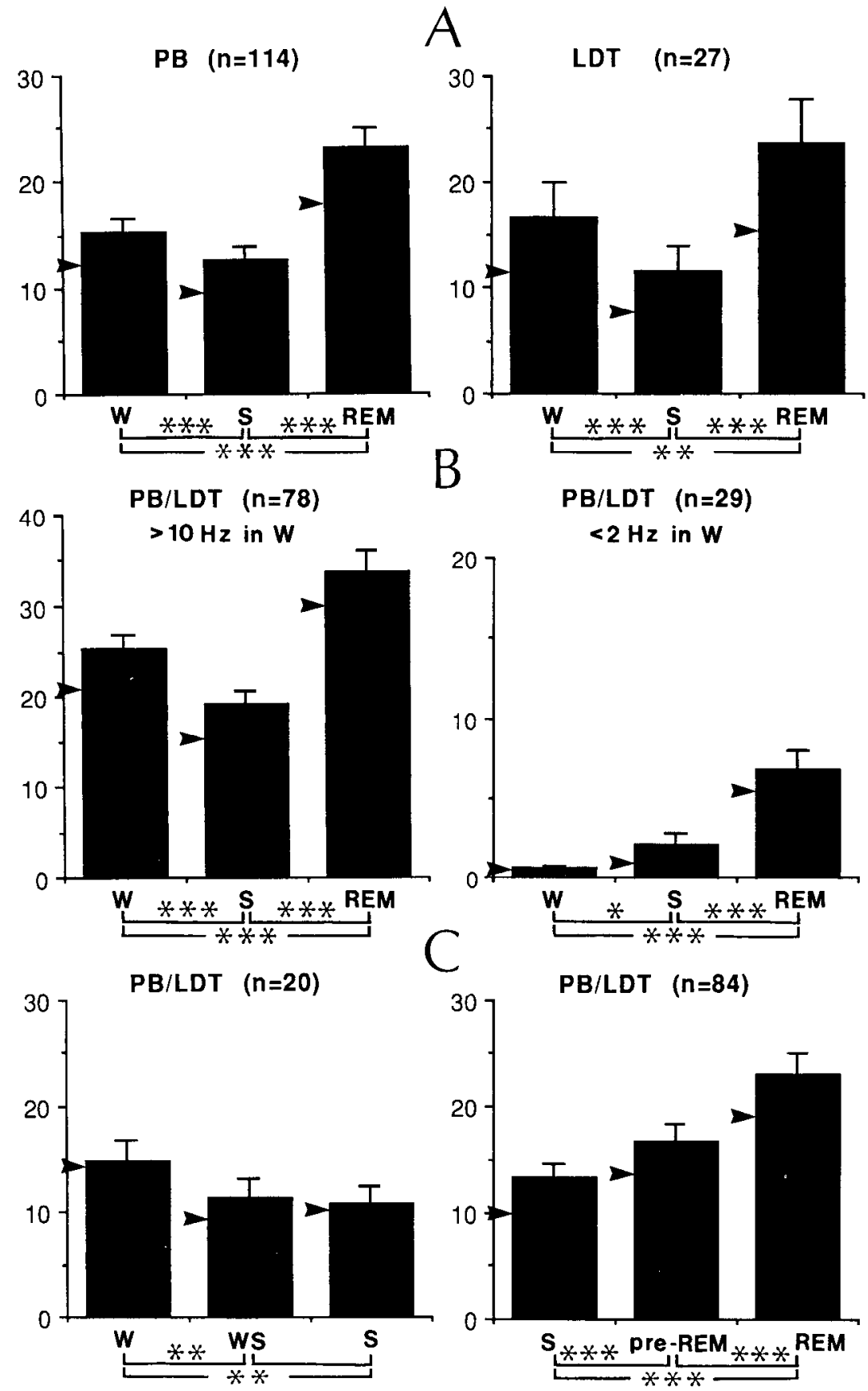

Figure 5. Firing rates of $\mathrm{PB}$ and LDT neurons during full-blown states and transitional cpochs of the wake-slcep cycle. $A$, Mean (columns) with SEs, median (arrowheads), and statistical differences in samples of $114 \mathrm{~PB}$ cells and 27 LDT cells during W, S, and REM sleep. $B$, Firing rates in 2 samples of PB/LDT cells distinguished by their relatively high $(>10 \mathrm{~Hz})$ and low $(<2$ $\mathrm{Hz}$ ) discharge rates during $W$. C, Firing rates during the transitional epoch WS from $\mathrm{W}$ to $\mathrm{S}$ in a sample of $20 \mathrm{~PB} / \mathrm{LDT}$ cells, and during the transitional epoch pre-REM from $S$ to $R E M$ in a sample of $84 \mathrm{~PB} / \mathrm{LDT}$ cells. In $B$ and $C$, same graphic representations as in $A$. Statistical differences between states indicated by 1 asterisk $(p<0.01), 2$ asterisks $(p<0.005)$, and 3 asterisks $(p<0.0005)$.

\section{Tonically increased firing rates during EEG-desynchronized states}

Analyses of firing rates in groups of PB $(n=114)$ and LDT ( $n$ $=27$ ) cells during full-blown states showed that the lowest rates occurred in $\mathrm{S}$, with medium rates in $\mathrm{W}$ and highest rates in REM (Fig. 5A). However, these values greatly underestimate the differences between the increased rates of spontaneous firing during EEG-desynchronized states compared with EEG-synchronized sleep. Indeed, as shown in the next section (see Figs. 9-13), the overall discharge rate in $\mathrm{S}$ comprised periods during which precursor signs of increased firing appeared about 20-60 sec before the onset of W or REM sleep. Conversely, the overall discharge rate in $\mathrm{W}$ was reduced because the period analyzed as $\mathrm{W}$ comprised the decreased firing heralding the transitional WS epoch. Despite these fluctuations of discharges, the differences between $\mathrm{S}$ and both EEG-desynchronized states were statistically significant $(p<0.0005)$ in both PB and LDT cell samples (Fig. 5A). There were no statistically significant differences between firing rates of PB and LDT cells in all states $(p$ $>0.1$ ).

Since we observed striking differences between a majority of $\mathrm{PB} / \mathrm{LDT}$ cells with high discharge frequencies in $\mathrm{W}$ and a less numerous $\mathrm{PB} / \mathrm{LDT}$ neuronal class with low discharge rates in $\mathrm{W}$, we analyzed the firing rates of the 2 cell groups, 1 with discharges exceeding $10 \mathrm{~Hz}$ during $\mathrm{W}$, the other displaying firing rates below $2 \mathrm{IIz}$ during the same state (Fig. 5B). The fastdischarging PB/LDT cells $(n=78)$ increased their firing rates 

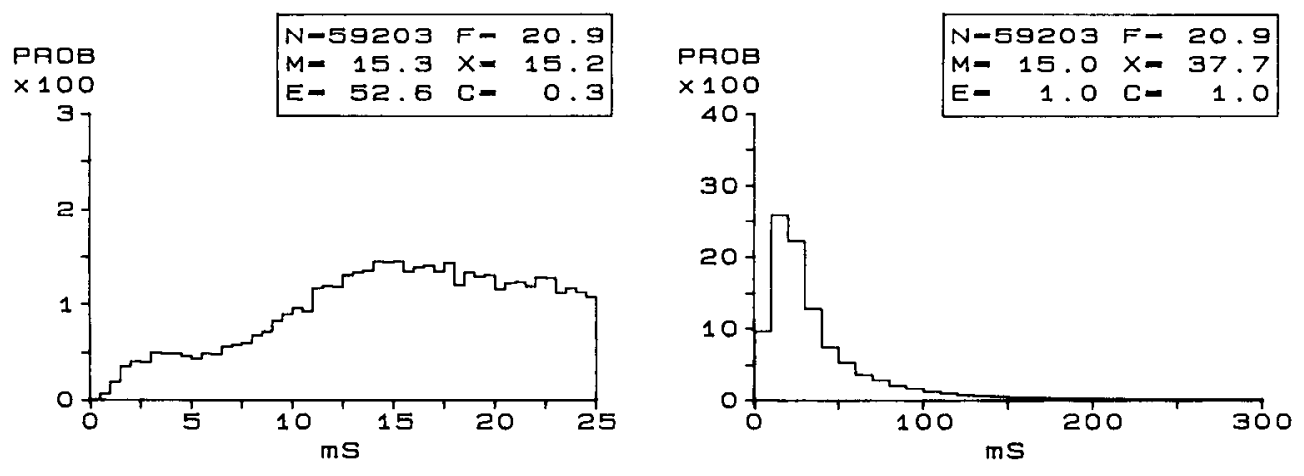

ISIH AVG-S
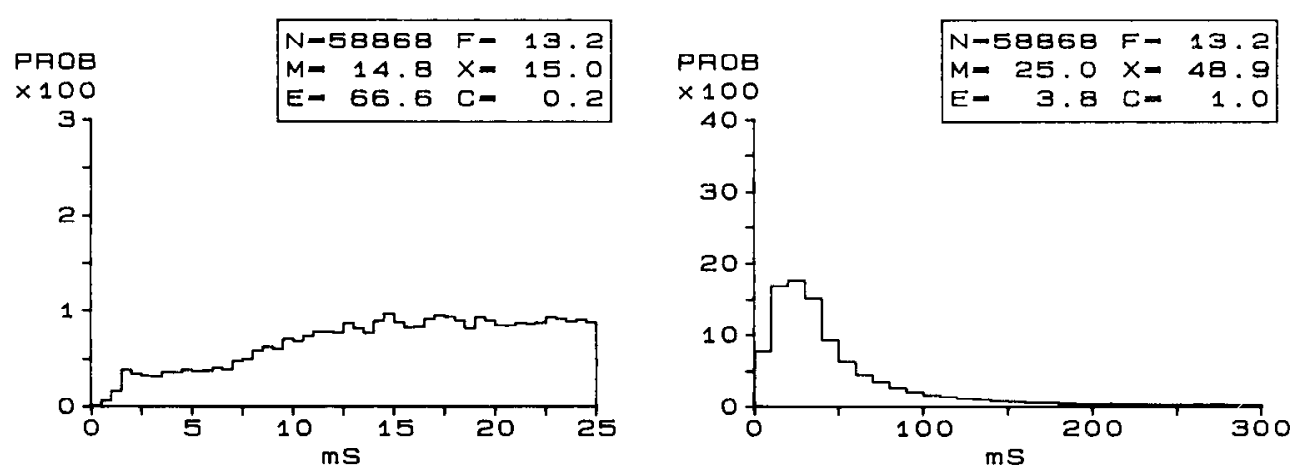

ISIH AVG-REM

Figure 6. Pooled interspike interval histograms (ISIHs) in a group of $34 \mathrm{~PB}$ / LDT cells with thalamic projections during W, S, and REM sleep. For each state, 2 ISIHs were computed, with 0.5 msec bins (left) and 10-msec bins (right). Symbols: $N$, number of intervals; $F$, discharge frequency/sec; $M$, interval mode (in msec); $X$, mean interval (in $\mathrm{msec}$ ); $E$, percentage of intervals in excess of the depicted time range; $C$. coefficient of variation. See comments in text.
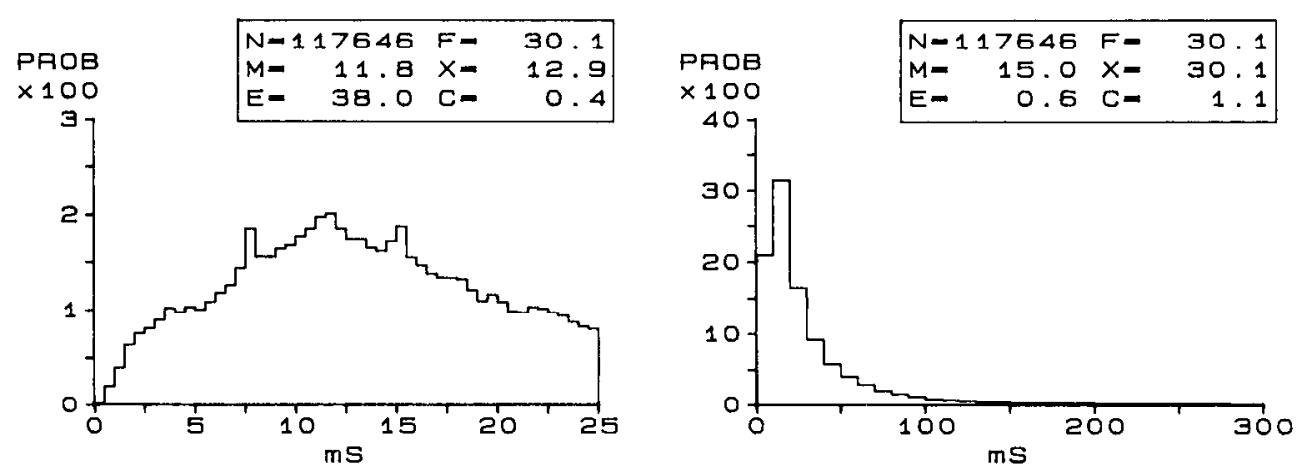

during both $\mathrm{W}$ and REM sleep, as compared to $\mathrm{S}$; differences between all states were significant $(p<0.0001)$. By contrast, slowly discharging PB/LDT neurons $(n=29)$ increased their firing rates from $\mathrm{W}$ to $\mathrm{S}(p<0.01)$, and further increased their discharge frequencies to REM sleep $(p<0.0001)$. There were no significant differences between 1 group and the other as to the percentages of cells with antidromically identified thalamic projections ( $44 \%$ in the fast-discharging group, $56 \%$ in the slowly discharging group).

The pooled ISIHs of 34 thalamic-projecting PB/LDT cells (Fig. 6) that could be recorded for sufficient periods of time in all states show that (1) the average firing rates were $20.9 \mathrm{~Hz}$ in $\mathrm{W}, 13.2 \mathrm{~Hz}$ in $\mathrm{S}$, and 30.1 in REM sleep, with differences between all states at $p<0.0005$; of those 34 cells, 29 increased discharge rates from $\mathrm{S}$ to $\mathrm{W}$, and all increased rates from $\mathrm{S}$ to REM; (2) very short ( $<5 \mathrm{msec}$ ) intervals, reflecting high-frequency bursts, represented only $3.4,2.7$, and $6.7 \%$ of the intervals in W, S, and REM, respectively; very long (>200 msec) intcrvals also constituted negligible proportions: $1.0 \%$ in $\mathrm{W}$, $2.5 \%$ in $\mathrm{S}$, and $0.7 \%$ in REM sleep; (3) consequently, most intervals were concentrated within a medium class, between 10 and $40 \mathrm{msec}$; (4) the ratio between the mean interval and the interval mode for intervals between 0 and $25 \mathrm{msec}$ approached 1, a sign of the ISIH symmetry; (5) for the same interval class $(0-25 \mathrm{msec})$, the coefficient of variation was very small $(<0.5)$ during all states.

Twenty-two PB cells exhibited an oscillatory pattern of discharge consisting of trains of single spikes occurring periodically, 
A Unit

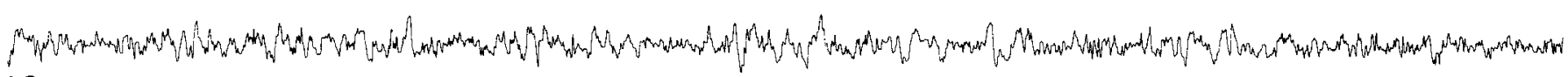
LG

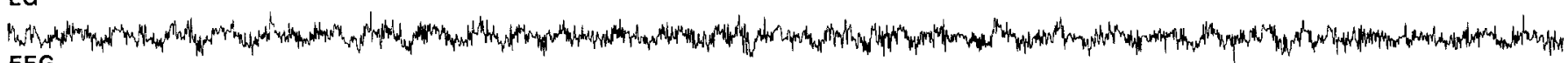
EEG

EOG

\section{EMG}

B

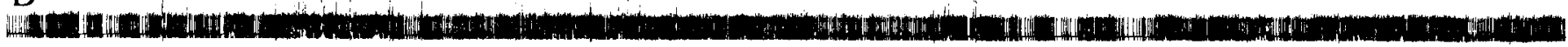

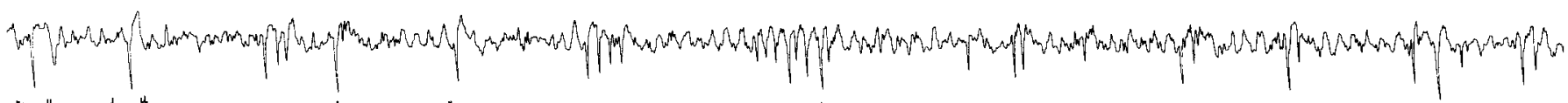
1)

C

Com

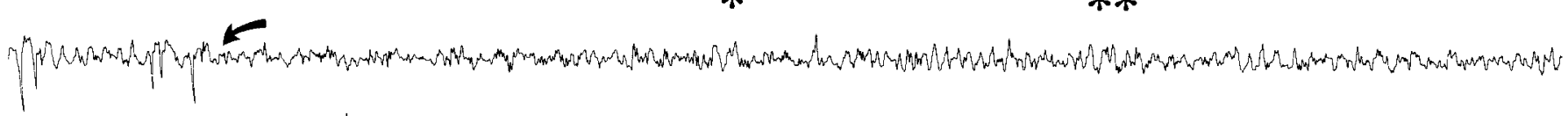

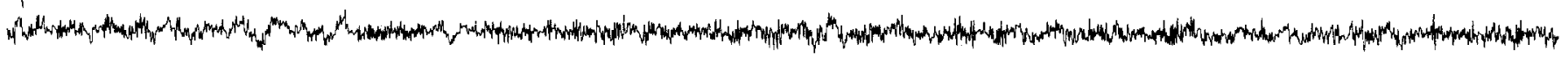
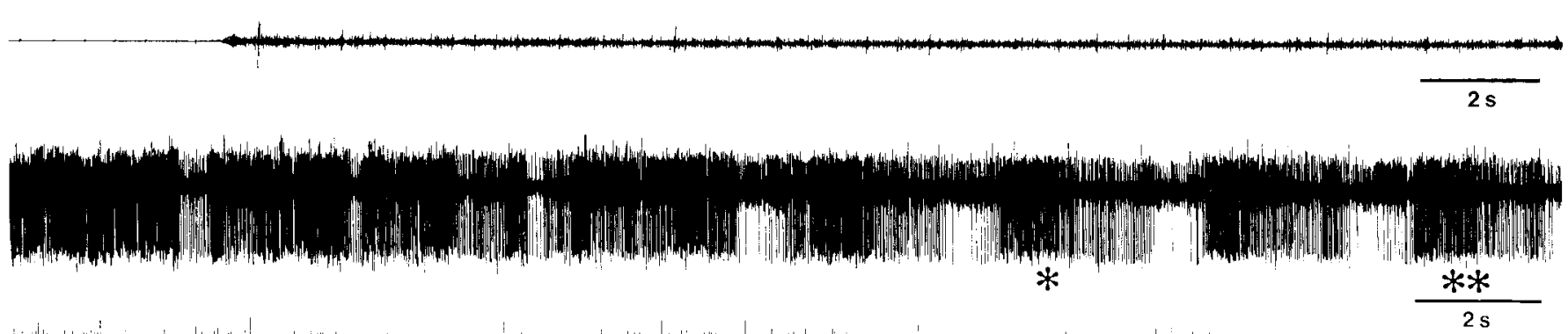

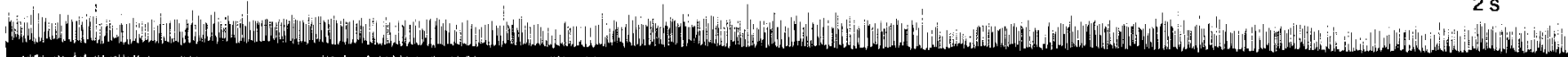

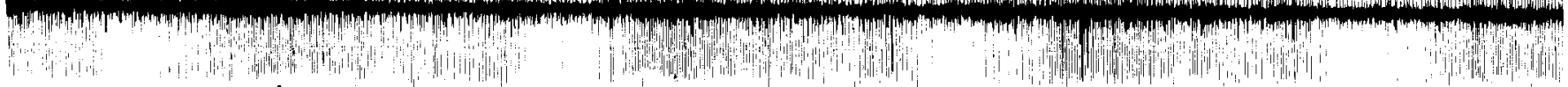

*

**

$1 \mathrm{~s}$

Figure 7. Oscillatory discharge patterns in a PB cell projecting to the medial part of the thalamus. The 5 ink-written traces represent unit activity (see large spike in oscilloscopic traces at bottom) and physiological correlates of waking-sleep states. $A$, During quiet W; $B$, during REM sleep; $C$, arousal (arrow) from REM sleep. Below, 2 traces of original action potentials (big spike) at 2 different speeds, depicting the spike trains marked by 1 and 2 asterisks in $C$.

generally with a rhythm of $0.8-1 \mathrm{~Hz}$. Autocorrelograms in 7 such cells during various states of vigilance revealed that the rhythmicity was particularly pronounced during $\mathrm{W}$ and $\mathrm{S}$ and that it was obliterated during REM sleep in parallel with the increased neuronal firing during the latter state. The neuron depicted in Figures 7 and 8 discharged at $32.1 \mathrm{~Hz}$ in $\mathrm{W}, 28.3$
$\mathrm{Hz}$ in $\mathrm{S}$, and $52 \mathrm{~Hz}$ in REM sleep. The clock-like recurrence of spike trains at about $0.9 \mathrm{~Hz}$ during $\mathrm{W}$ (Fig. 7A), visible in the multiple peaks of the autocorrelogram in Figure 8 , disappeared with the increased firing rate during REM sleep (Fig. 7B). The rhythmic spikc trains rcappearcd upon awakening from REM, this time with markedly increased duration of spike trains, re- 

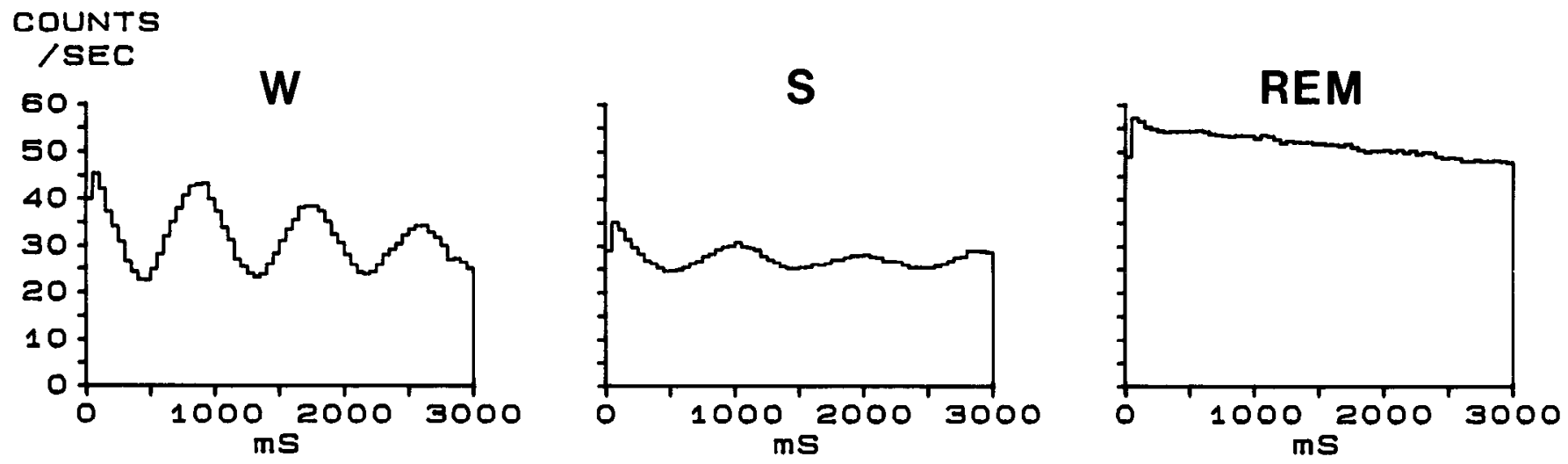

Figure 8. Autocorrelograms of the unit depicted in Figure 7 (big spike) during W, S, and REM sleep.

curring at $0.3 \mathrm{~Hz}$ (Fig. 7C). Inspection of spike trains (bottom oscilloscopic traces in Fig. 7) reveals an acceleration-deceleration discharge pattern, reaching $90-100 \mathrm{~Hz}$ in the middle of the train.

Precursor changes in PB/LDT cell firing heralding shifts in the state of vigilance

Figure 9 shows the continuously changing firing rate of a tonically discharging PB neuron across the waking-sleep cycle. The rate values in each state matched those found in the 114 cell sample analyzed as a group. The firing rate in $\mathrm{W}$ diminished progressively before the appearance of EEG signs marking the transitional WS epoch, and the firing rate in $\mathrm{S}$ increased while the EEG was still fully synchronized, $30 \mathrm{sec}$ before the transitional pre-REM epoch leading to REM sleep. This picture indicates that neuronal discharges in mesopontine cholinergic nuclei are not "steady." Therefore, we investigated the chronology of firing during transitional epochs of the waking-sleep cycle.

In a sample of $20 \mathrm{~PB} / \mathrm{LDT}$ cells, the decrease in firing rate from $\mathrm{W}$ and WS was significant $(p<0.005)$, whereas no significant differences were found between WS and $S$ (see Fig. $5 C$ ).
The dynamic changes in a single PB cell and a group $(n=5)$ of $\mathrm{PB} / \mathrm{LDT}$ neurons showed a decrease in their firing rates during W more than $10 \mathrm{sec}$ before the first spindle sequence indicating the onset of the WS epoch (Fig. 10, $A, B$ ). Thus, the decrease in discharge rates essentially occurred before WS, and no further decrease in rate was observed from WS to $S$.

Conversely, during the transition from $\mathrm{S}$ to $\mathrm{W}, \mathrm{PB}$ neurons increased their firing rates about $15-20 \mathrm{sec}$ in advance of the EEG desynchronization (Fig. 11) and well before the increased muscular tone and eye movements that appeared later on.

The transition from $\mathrm{S}$ to REM was analyzed in $84 \mathrm{~PB} / \mathrm{LDT}$ cells. The increased rate from $S$ to pre-REM and, further, from pre-REM to REM was significant at $p<0.0001$ (see Fig. 5C). SMFs and cumulative histograms showed that a significant ( $p$ $<0.05)$ increase in discharge frequency occurs about $60 \mathrm{sec}$ before the onset of EEG desynchronization in REM sleep (Figs. $12,13)$. Since this period comprises $\mathrm{PGO}$ waves and some of these neurons were also PGO-on (see following paper), we made a separate analysis by taking as time 0 the onset of the pre-REM epoch. This analysis showed a significant $(p<0.05)$ increase in firing rates from $S$ to pre-REM, 25 sec before the appearance

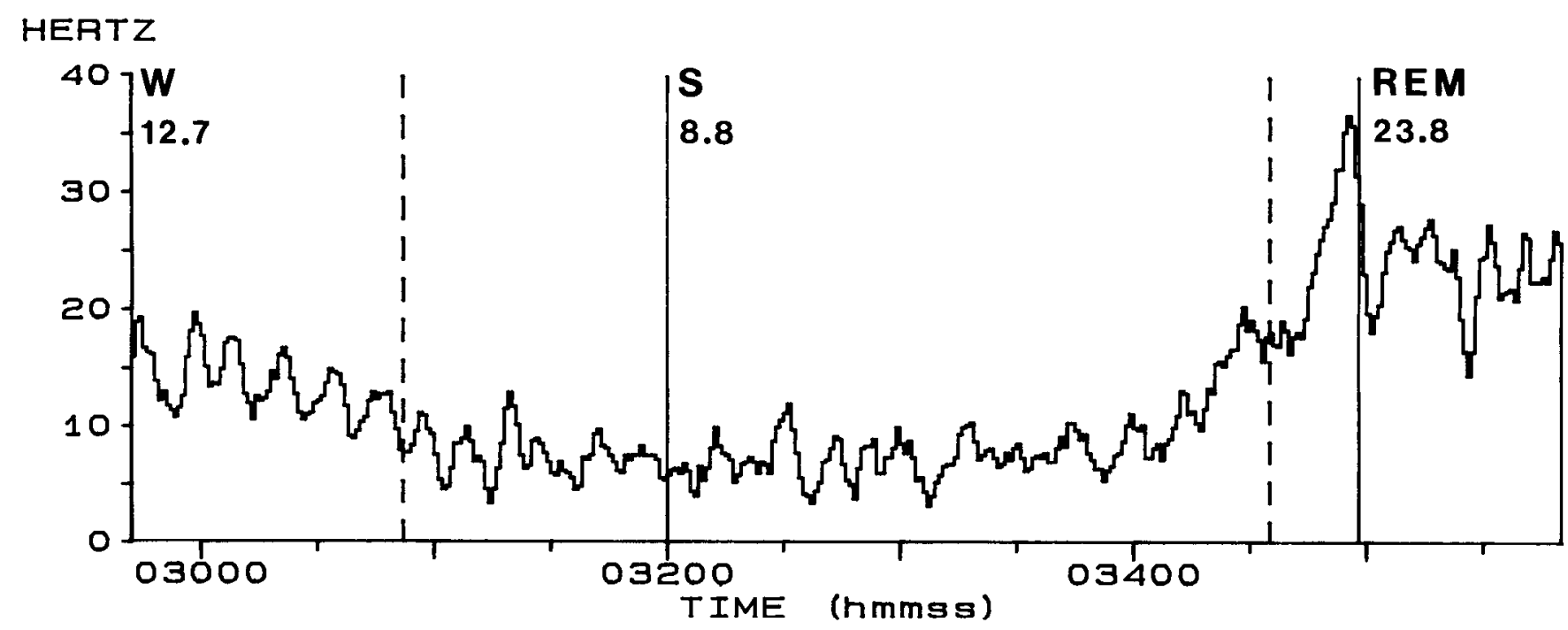

Figure 9. Sequential firing rate (SMF) of a PB cell antidromically activated from the rostral intralaminar thalamus across the wake-sleep cycle. Abscissa indicates real time. Mean firing rates during W, S, and REM are indicated (Hz) for each state. Transitional WS and pre-REM epochs are indicated by vertical interrupted lines (at 0:30:53 and 0:34:34, respectively). Note cyclic activity toward the end of W state (see also Fig. $11 B$ ). 


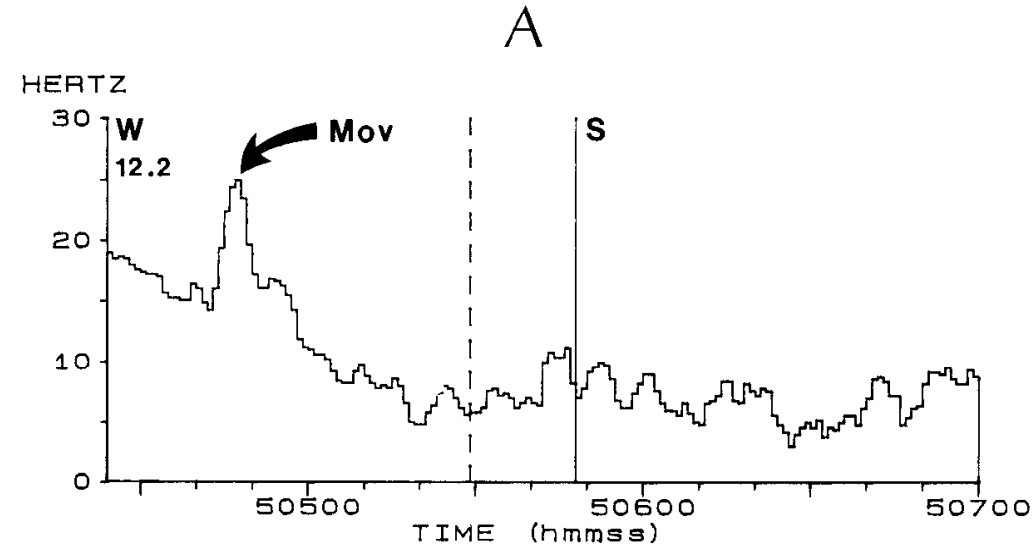

B

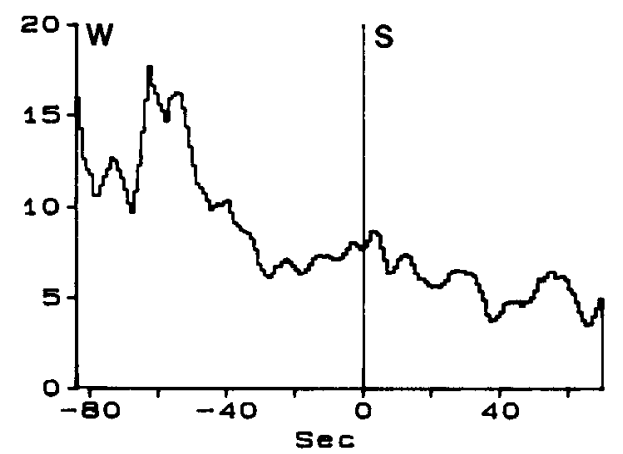

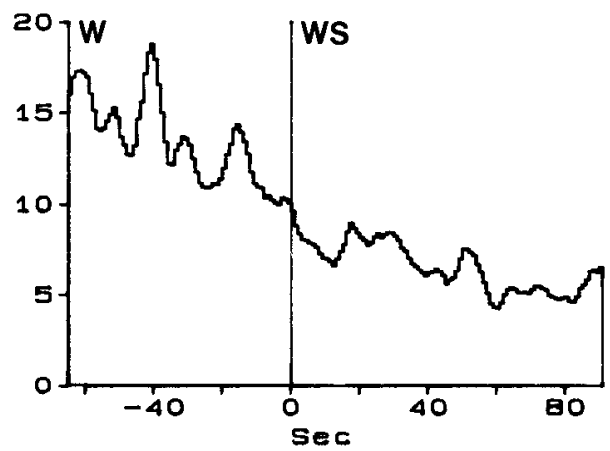

Figure 10. SMFs in a thalamic-projecting PB cell $(A)$ and a group of $5 \mathrm{~PB} /$ LDT cells $(B)$ during transition from $\mathrm{W}$ to $\mathrm{S}$ and $\mathrm{W}$ to WS. In $A$ (same type of graph as in Fig. 9), dashed line at 5:05: 29 indicates the onset of WS; arrow in $W$ indicates gross body movement (Mov). In $B$, time 0 is taken for onset of $S$ and WS. of the first PGO wave marking the onset of the pre-REM transitional epoch (Fig. 13).

\section{Enhanced antidromic and synaptic excitability of $P B / L D T$ cells during $E E G$-desynchronized behavioral states}

The antidromic response probability rose by $35-50 \%$ from both $\mathrm{W}$ and $\mathrm{S}$ states to REM sleep (Fig. 14; see action potential and bin in peristimulus histogram marked by asterisks). Moreover, in some neurons antidromic invasion was detected selectively during REM sleep (Fig. 15A). The latter finding further emphasizes that the percentage of antidromically identified cells $(10 \%)$ in our sample is a gross underestimation (see also comments in the section on data base and neuronal identification).

The degree of increased synaptic excitability during EEGdesynchronized states varied from cell to cell, but was consistently present. The increased probability of neuronal responses to orthodromic volleys from $\mathrm{S}$ to either $\mathrm{W}$ and REM sleep was in the range of 12 and $25 \%$ in some neurons (Fig. 14), but could reach $40-70 \%$ (Fig. $15 B$ ) and even $80 \%$ (Fig. 15A) in other cells. REM sleep was by far the state with the highest neuronal responsiveness. This was even observed in some cells whose spontaneous firing rate was lower in REM than in W, whereas their synaptic excitability was much higher (85\%) during REM sleep than during $\mathrm{W}$ (Fig. 16).

\section{Discussion}

Some remarks on the chemical code and input-output organization of mesopontine reticular neurons

The only safe identification of cholinergic neurons can be achieved by combining intracellular staining and ChAT immunohistochemistry. At this time, it appears impossible to re- alize these procedures in a behaving preparation, with recordings lasting for several weeks or more. Nonetheless, it is very likely that the overwhelming majority of neurons recorded in this study were cholinergic for the following reasons. (1) We recorded more than $90 \%$ of our PB sample at stereotaxic levels A1-P1 (see these levels in the NADPH-diaphorase-stained sections in Fig. 1). At this level, cholinergic neurons represent $85 \%$ of cells, whereas monoamine-containing neurons constitute only 15\% (see Tables III and IV of Webster and Jones, 1988). Monoaminergic neurons become an important population, even exceeding the number of cholinergic cells, at more caudal levels, in the parabrachial nucleus. (2) The proportions of cholinergic and monoaminergic neurons in the LDT nucleus are 67 and $33 \%$, respectively (see Tables I and III in Jones and Webster, 1988). Most monoamine-containing neurons are located in the extreme lateral part of the LDT nucleus, adjacent to the locus coeruleus, a region where we systematically avoided recording neurons. The repeated claim that cat's locus coeruleus contains a significant number of cholinergic cells probably derives from the admixture of cholinergic and monoaminergic cells at the limit between LDT and locus coeruleus (see the red-stained, non-NADPH-diaphorase neurons in the present Fig. $1 F$ ). (3) I hat monoaminergic elements constitute a negligible proportion of neurons in our samples is shown by the fact that only 3 cells out of the $114 \mathrm{~PB}$ cell and 27 LDT cell samples (2\%) ceased discharging in REM sleep. The latter feature is characteristic of monoaminergic neurons in dorsal raphe (McGinty and Harper, 1976; Lydic et al., 1983) and locus coeruleus (Hobson et al., 1975; Aston-Jones and Bloom, 1981; see details in Steriade and McCarley, 1990).

The axonal conduction velocities of thalamic projections can- 


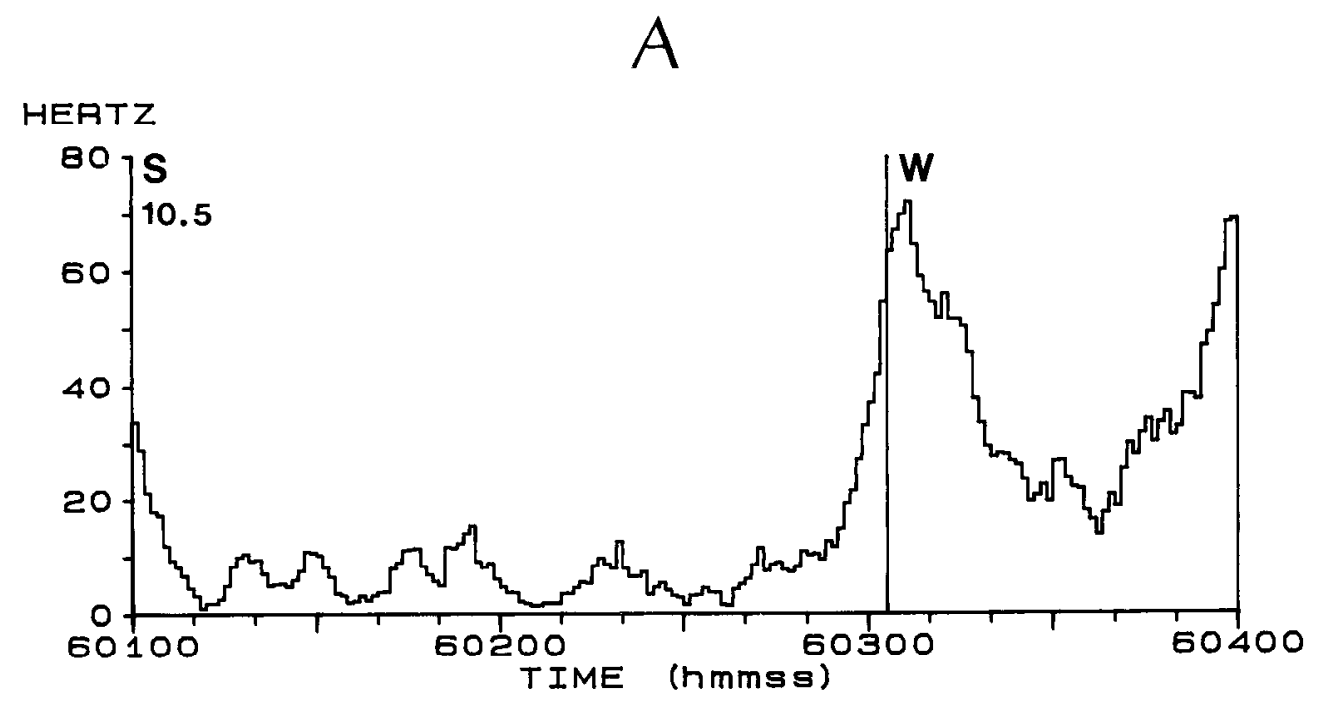

Figure 11. SMFs in a thalamic projecting $\mathrm{PB}$ cell $(A)$ and a group of $7 \mathrm{~PB} /$ IDT cells $(R)$ during transition from $S$ to W. Same type of graphs as in Figures 9 and 10. Dotted line in $B$ indicates the discharge level between -80 and -20 sec.

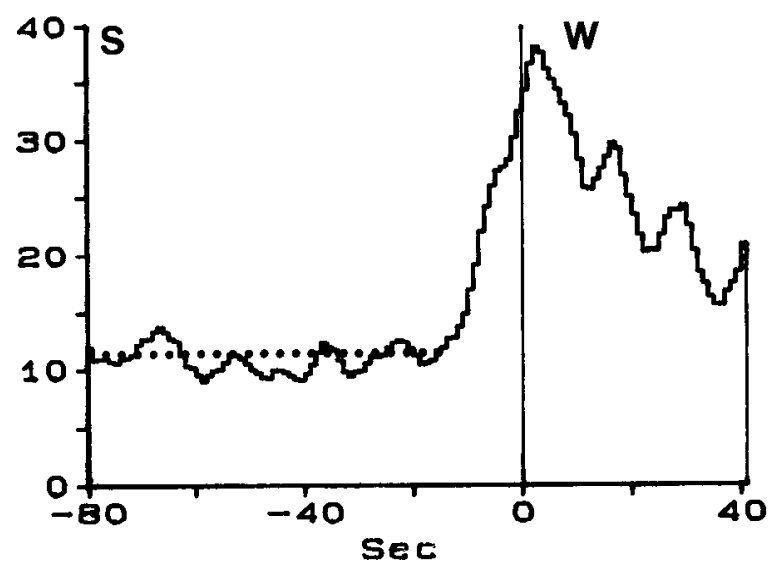

not be inferred because we have no evidence whether we stimulated the parent axon or axonal terminals and only 1 stimulating electrode was inserted along each projection pathway to various thalamic nuclei. However, crude estimates from the histogram of antidromic response latencies (Fig. $3 B$ ) suggest that the conduction velocities of PB/LDT axons toward medial and intralaminar thalamic nuclei (ranging between 4 and $8 \mathrm{~m} / \mathrm{sec}$ ) are higher than those projecting to the reticular and lateral geniculate thalamic nuclei $(1.3-4 \mathrm{~m} / \mathrm{sec})$. The inferred conduction velocities of $\mathrm{PB}$ axons to the lateral geniculate nucleus fit in with the axonal diameters $(0.3-0.7 \mu \mathrm{m})$ measured in an anterograde tracing study (Uhlrich et al., 1988). These values are also consistent with previous data showing that the antidromic response latencies of mesopontine reticular neurons to intralaminar thalamic stimulation are shorter than those evoked by lateral geniculate stimulation (Ropert and Steriade, 1981; Ahlsén, 1984). The low conduction velocities of mesopontine tegmental neurons projecting to the reticular thalamic nucleus corroborate the conduction velocities in the reciprocal, descending pathway (Parent and Steriade, 1984).

The great number of $\mathrm{PB} / \mathrm{LDT}$ cells that were synaptically driven from the thalamus may seem surprising since the conventional wisdom is that there are few, if any, descending pro- jections from the thalamus to the brain stem. It must be recognized that stimulation of certain thalamic nuclei (e.g., the reticular sheet) may coactivate corticofugal axons coursing in the adjacent internal capsule. Also, thalamic stimulation may activate by axon reflex some fiber systems that originate in the lower medulla or spinal cord and collateralize to the PPT nucleus. However, many of these orthodromic responses are ascribable to thalamic descending projections that were demonstrated in retrograde and anterograde transport studies to arise in caudal and rostral intralaminar nuclei (Parent and Steriade 1981), reticular thalamic complex (Parent and Steriade, 1984), and ventral part of the lateral geniculate complex (Higo et al., 1989).

Discharge properties of PR/LDT cells: a comparison with $P P T / L D T$ neurons in vitro and with other brain-stem reticular neurons during waking-sleep states

We have documented the tonicity of $\mathrm{PB} / \mathrm{LDT}$ neurons by firstorder measures indicating small mean-mode interval ratio and relatively small spread around the mode. Thalamocortical neurons display about $30 \%$ of intervals shorter than $5 \mathrm{msec}$ in $\mathrm{S}$ (Glenn and Steriade, 1982), a state in which they selectively fire high-frequency bursts; in contrast, PB/LDT cells display less 


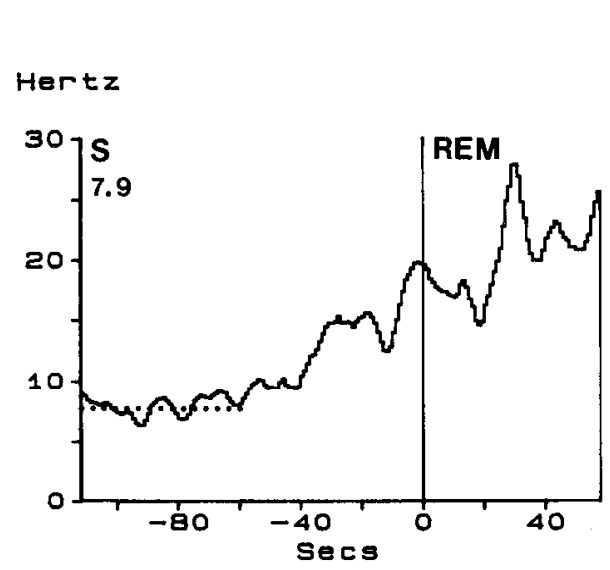

A

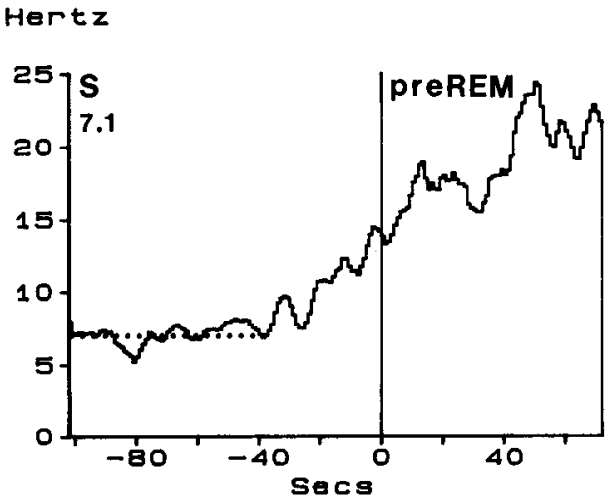

B
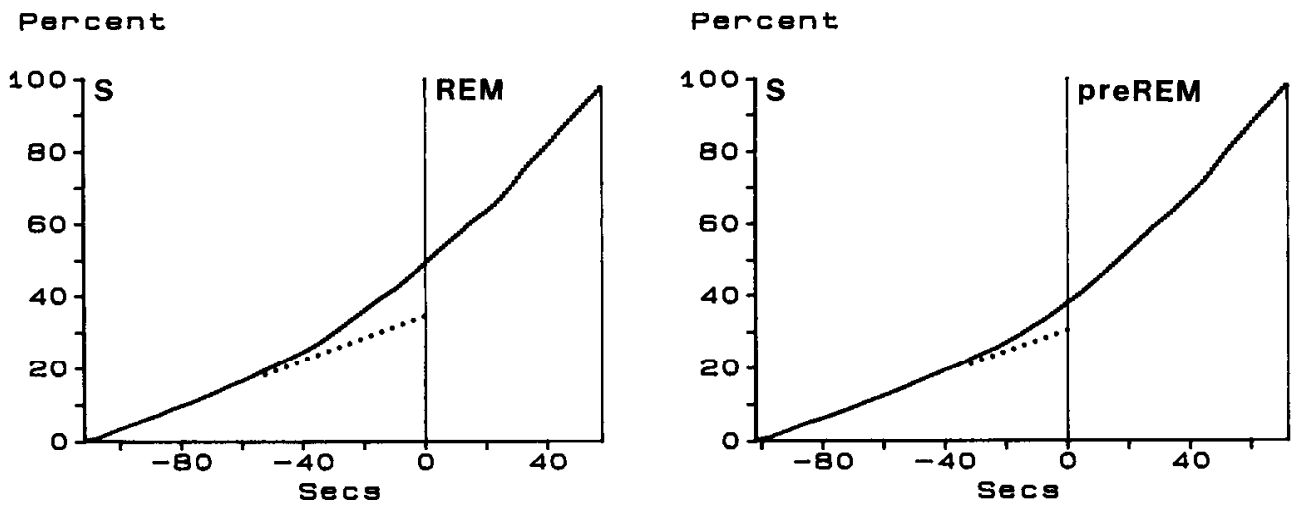

Figure 12. SMFs $(A)$ and cumulative histograms $(B)$ in 21 thalamic-projecting $\mathrm{PB} / \mathrm{LDT}$ cells during transitions from $S$ to $R E M$ and $S$ to pre-REM. SMFs as in previous figures. Dotted lines in $A$ and $B$ indicate the discharge rate in $\mathrm{S}$.

than $4 \%$ of such intervals in $\mathrm{W}$ and $\mathrm{S}$, and less than $7 \%$ in REM sleep, when some tonic PB/LDT cells are also PGO-on bursting elements (see following paper).

The contention that $75 \%$ of $\mathrm{PB} / \mathrm{LDT}$ neurons analyzed in this paper are tonic in nature and do not usually display high-frequency spike bursts accords well with in vitro studies of PPT neurons (Leonard and Llinás, 1987, 1990; Kang and Kitai, 1990). These authors have reported that a majority of cholinergic neurons, retrogradely labeled from the thalamus prior to preparing the slices, have intrinsic properties well suited to the tonic, single-spike repetitive firing described in the present paper. In particular, must PPT cells do not have the low-threshold calcium conductance (LTS) which underlies high-frequency spike bursts. Instead, they have a transient outward potassium conductance termed $g_{\mathrm{A}}$. Note, however, that a newly discovered subsample of $\mathrm{PB} / \mathrm{LDT}$ cells discharge high-frequency spike bursts, preceding by $20-30 \mathrm{msec}$ the thalamic PGO waves, on a background of tonically increased firing rate during REM sleep; those neurons also display tonic discharge patterns during $\mathrm{W}$ and $\mathrm{S}$ states (Steriade et al., 1990b). These bursts are obviously different from those triggered by LTSs as they arise at a relatively depolarized level. These presumed high-threshold burst-neurons, as well as the cells displaying only LTSs in the PPT (Leonard and Llinás, 1987, 1990; Kang and Kitai, 1990) and LDT (Wilcox et al., 1989) nuclei, will be considered in the following paper, in relation to the transfer of the PGO signal to the thalamus.

We speculate that the $g_{\mathrm{A}}$ conductance of PPT neurons is involved in the patterning of oscillatory behavior depicted in the present Figures 7 and 8. Indeed, the silent periods between the rhythmic spike trains are presumably due to sequential activation of $g_{(\mathrm{Ca}) \mathrm{k}}-g_{\mathrm{A}}$ by the repetitive firing during the spike trains. The silent periods, shaping the rhythm of spike trains, are obliterated during REM sleep associated with an increased firing rate, similar to the inactivation of $g_{A}$ by membrane depolarization.

We will now compare the state-dependent changes in firing rate of neurons recorded in $\mathrm{PB} / \mathrm{LDT}$ cholinergic nuclei with those of neurons in other brain-stem reticular fields.

1. The similar features are high rates $(>10 \mathrm{~Hz})$ of discharges during both EEG-desynchronized states in most recorded elements and an increase in discharge frequency preceding the EEG desynchronization in W or REM sleep. Thalamic-projecting rostral midbrain reticular neurons increase their firing rates $15 \mathrm{sec}$ prior to EEG desynchronization upon arousal from $\mathrm{S}$ (Steriade et al., 1982) and bulbothalamic neurons in the magnocellular field increase.their discharge frequency at least $30 \mathrm{sec}$ prior to EEG desynchronization in REM sleep (Steriade et al., 1984). The neurotransmitters used by rostral midbrain and bulbothalamic reticular neurons are not known. The short-latency excitation of intralaminar thalamocortical neurons from the rostral midbrain core (Steriade and Glenn, 1982), where there are virtually no cholinergic or noradrenergic cells, suggests that excitatory amino acids may be involved in this type of thalamic activation from the midbrain core.

2. The PB/LDT cells differ from other brain-stem reticular ncurons with respect to the time course of increased neuronal activity during shifts from the state of S to EEG-desynchronized 


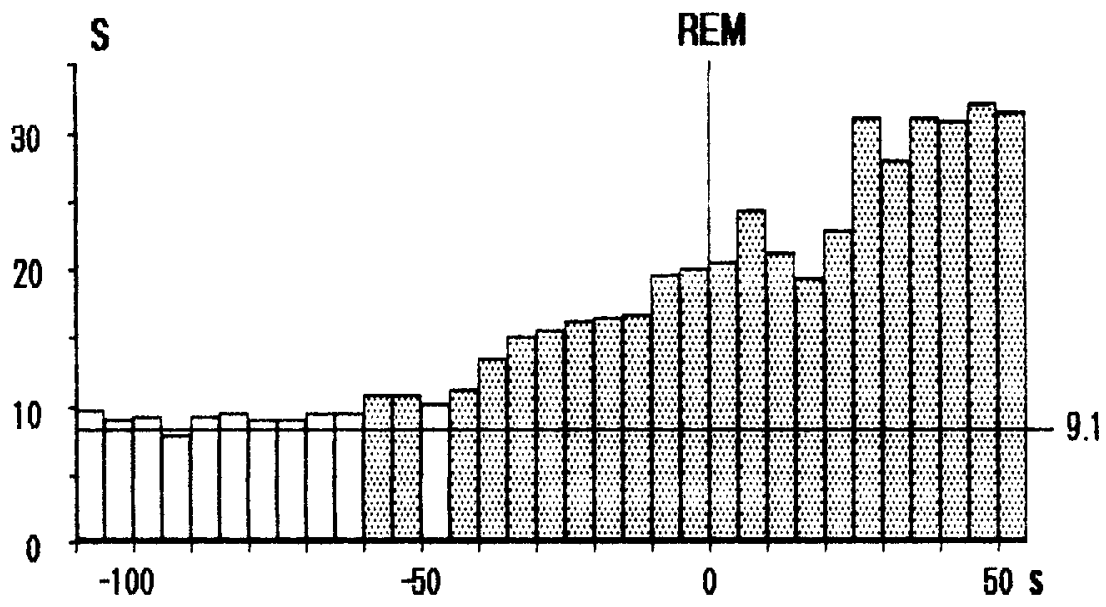

Figure 13. Statistical evidence in a pool of 21 thalamic-projecting PB/LDT cells showing increased firing rates 60 sec before EFG desynchronization in REM sleep and increased firing rate 25 sec before the first PGO wave marking the onset of the transitional pre-REM epoch. Shaded 5 -sec columns indicate bins with statistically significant $(p<$ 0.05 ) increased firing rates (see Materials and Methods).

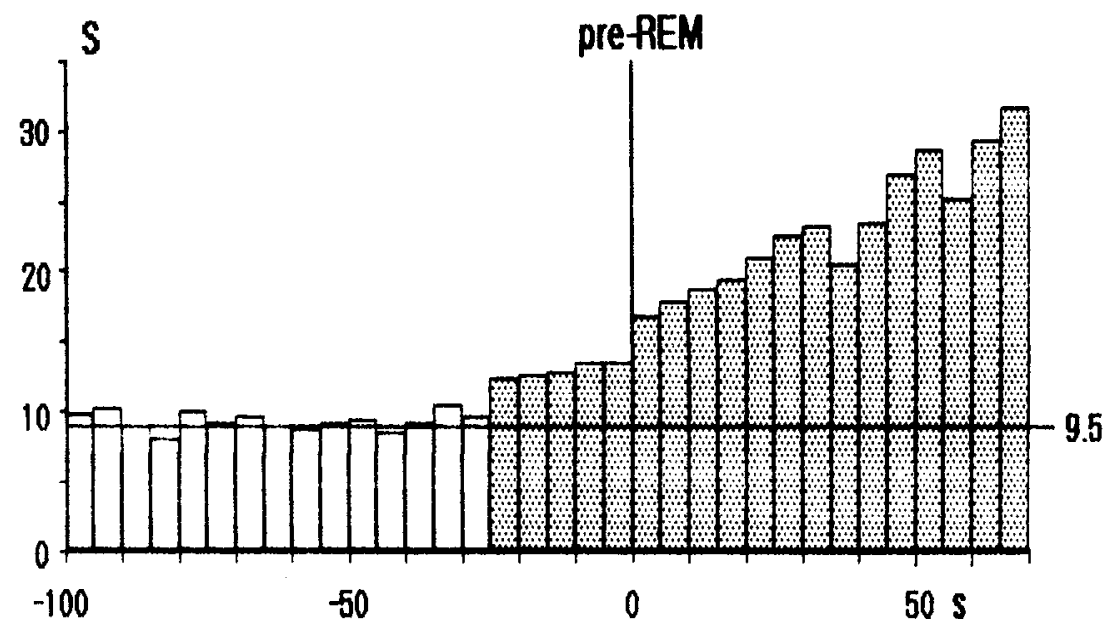

states. Our previous studies on rostral midbrain (Steriade et al., 1982) and bulbar reticular (Steriade et al., 1984) neurons have revealed precursor signs of increased activity heralding either W or REM sleep, respectively. The present data on PB/LDT neurons indicate that their enhanced activity reliably precedes both transitions from $\mathrm{S}$ to $\mathrm{W}$ and from $\mathrm{S}$ to REM slecp and that a decreased activity precedes the earliest signs of EEG synchronization during the $\mathrm{W}$-to-S transition. A recent study has also reported an increased firing rate of presumptive cholinergic brainstem reticular neurons before the onset of EEG desynchronization during REM sleep; increased rates occurred after the appearance of PGO waves (El Mansari et al., 1989). This aspect is similar to our previous data on bulbothalamic reticular neurons (see figure 10 in Steriade et al., 1984). Since some of the REM-on elements in the PB/LDT nuclei are also PGO-on, we performed a separate analysis in the present study and provided evidence that the increased firing rate of $\mathrm{PB} / \mathrm{LDT}$ cells precedes by $25 \mathrm{sec}$ the first PGO waves during transition from $\mathrm{S}$ to REM sleep.

The small group of PB/LDT neurons $(n=29)$ discharging at low rates $(<2 \mathrm{~Hz})$ during $W$ deserves special mention since those neurons, as distinct from all other thalamic-projecting brainstem reticular neurons, increased in a statistically significant manner their firing rate from $\mathrm{W}$ to $\mathrm{S}$, and further to REM sleep, reaching in this latter stage levels of spontaneous discharges that were 5-10 times higher than in $S$ and $W$. This progressively increased activity across the wake-sleep cycle is the inverse to the picture displayed by dorsal raphe neurons (McGinty and Harper, 1976; Trulson and Jacobs, 1979; Lydic et al., 1983). We refer only to dorsal raphe neurons, among other monoaminergic neurons with similar behavior during the wake-sleep cycle, because a manifest inhibitory action of serotonin on presumed cholinergic PPT cells has recently been reported in midbrain slices and the isolated/perfused brain (Khateb et al., 1989). It is then possible that the reciprocal images of $\mathrm{PB} / \mathrm{LDT}$ and dorsal raphe neurons reflect the progressive disinhibition of $\mathrm{PB}$ / LDT neurons with the transition from $\mathrm{W}$ to $\mathrm{S}$ and REM sleep.

\section{Role played by neurons of cholinergic PB/LDT nuclei in tonic ascending activation processes}

The demonstration that precursor signs of increased neuronal activity in cholinergic PB/LDT nuclei announce the shifts from EEG-synchronized sleep to either W or REM sleep raises questions concerning the events that occur during such long lead periods $(20-60 \mathrm{sec})$ preceding the onset of EEG desynchronization. It should be emphasized that these figures represent 

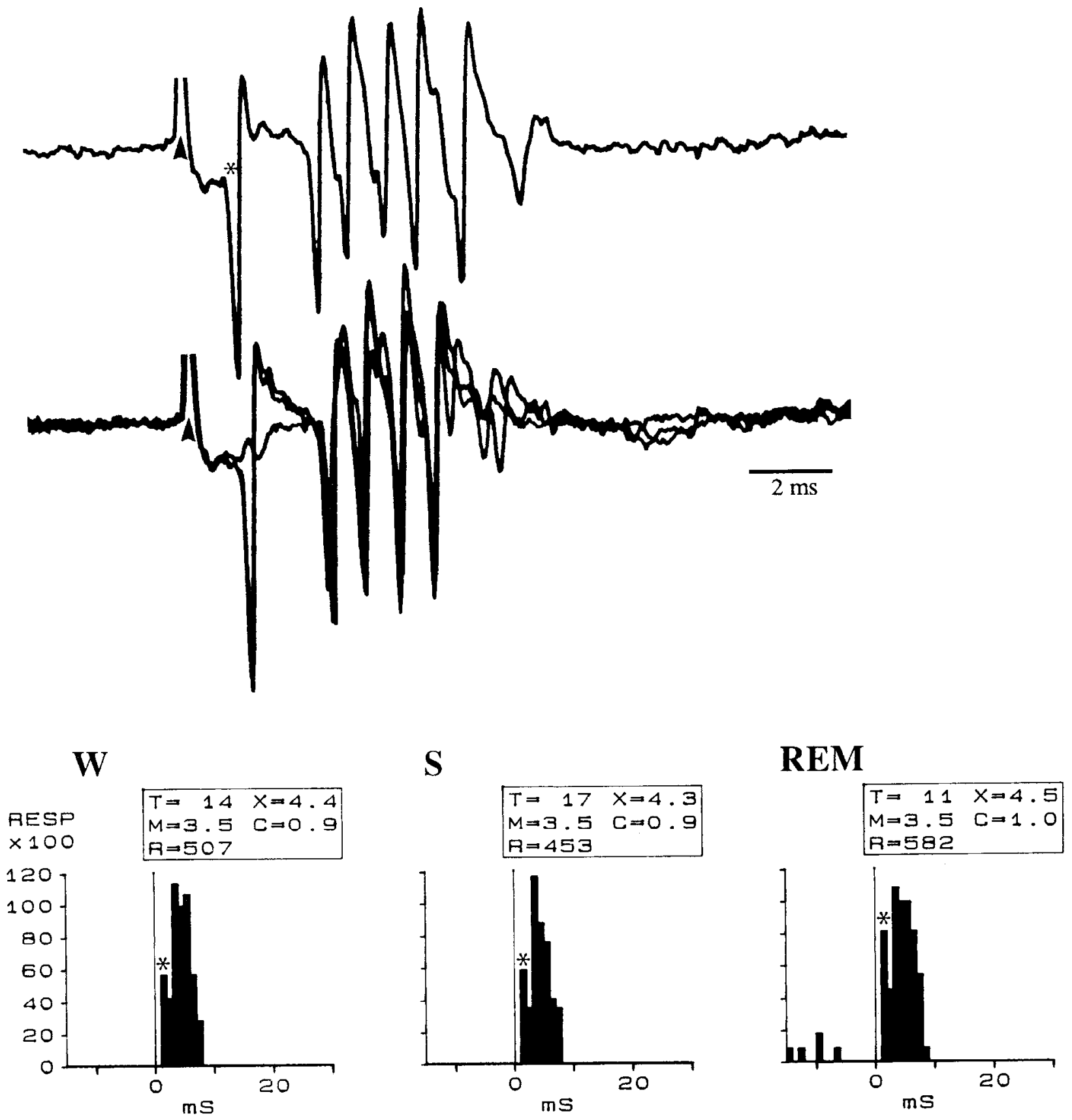

Figure 14. Enhanced antidromic responsiveness of PB cell during REM sleep. Top, Antidromically evoked spike from the lateral thalamus (asterisk), followed by a high-frequency burst of synaptically elicited discharges (note spike fragmentation during the burst). Below the single-sweep, a superimposition of 3 traces is depicted to show the presence of the high-frequency burst even when the antidromic invasion fails. Bottom, Peristimulus histograms ( $1 \mathrm{msec}$ bins) during wake-sleep states. Antidromic spikes in bins marked by asterisks. Symbols: $T$, number of trials; $X$, mean latency; $M$, latency mode; $C$, coefficient of variation; $R$, responsiveness defined as the total counts in the depicted range divided by the number of trials and expressed as a percentage.

values in pooled neurons and that a continuum of lead times has been observed in various neurons, from as long as $140 \mathrm{sec}$ to as short as $3 \mathrm{sec}$. A process of recruitment probably takes place within brain-stem networks before overt signs of changes in gross EEG activity. Extra- and intracellular studies of midbrain (Ropert and Steriade, 1981) and pontine (Ito and McCarley, 1987; McCarley et al., 1987) reticular neurons in unanesthetized behaving preparations have reached the conclusion that more than $90 \%$ of brain-stem neuronal responses to close and distant stimulation within the brain-stem core are excitatory in nature. This suggests that a cascade of excitatory events within brain-stcm networks prepares the time when a critical mass of thalamic-projecting neurons succeed in exerting their actions upon thalamic cells.

The actions of mesopontine cholinergic neurons upon the thalamus are known from in vitro studies using applications of cholinergic agonists and from in vivo experiments using intracellular recordings in preparations under anesthetics (other than barbiturates) that do not prevent the direct cholinergic excitation of thalamocortical neurons. The effects of acetylcholine 

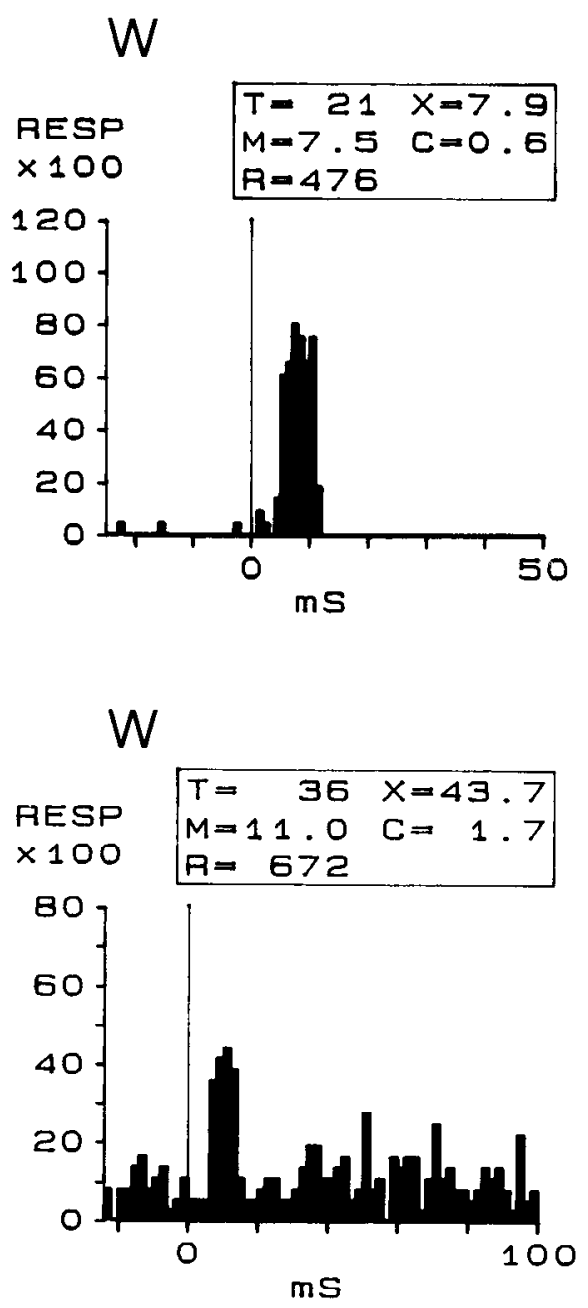

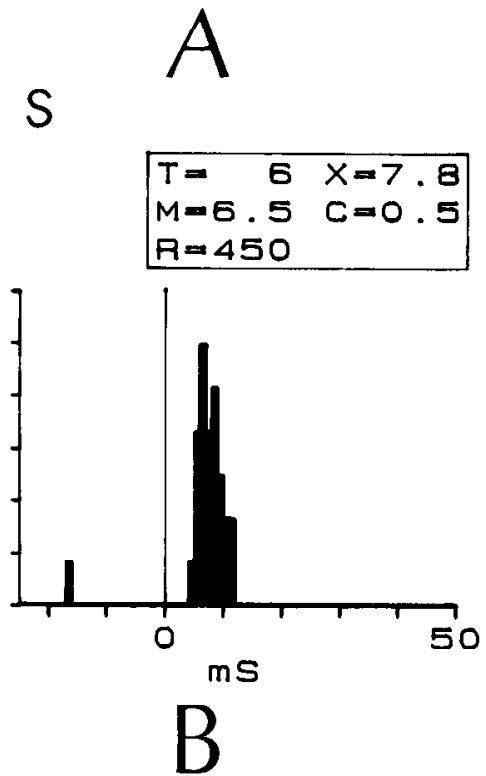

S
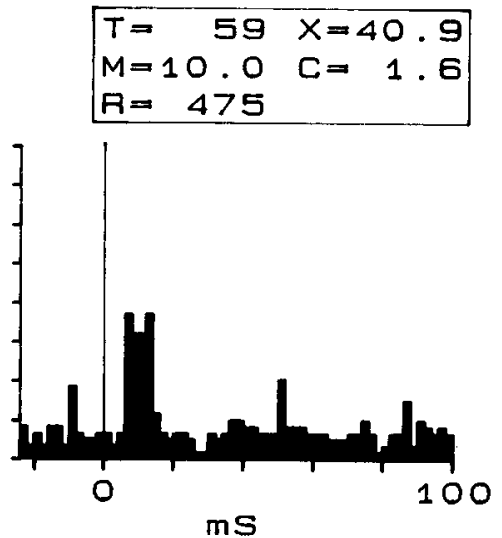

REM
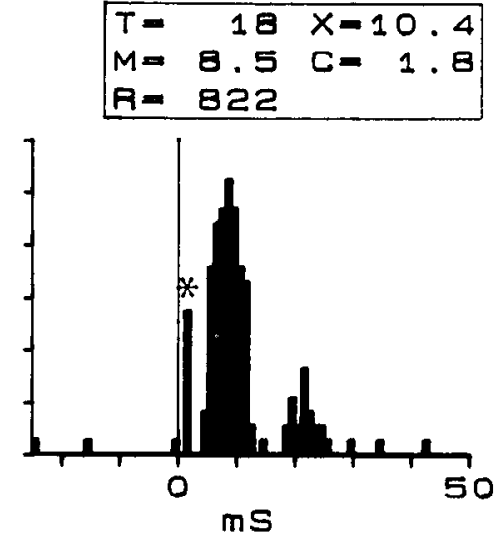

REM
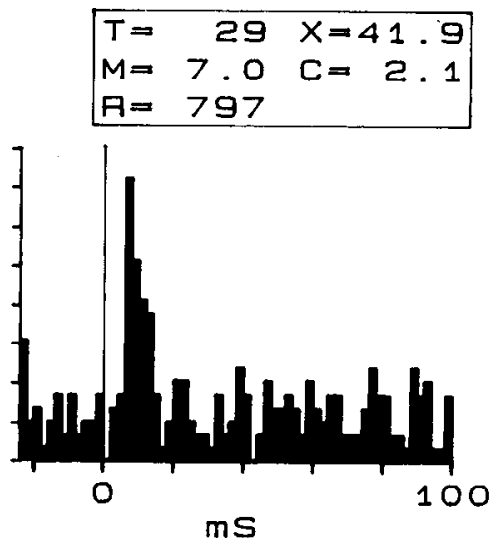

Figure 15. Antidromic and synaptic excitability of $\mathrm{PB}$ neurons during wake-sleep states. $A$, Antidromic activation (only during REM sleep, bin marked by asterisk) and synaptic excitation from 1 of the intermediate thalamic electrodes. $B$, Synaptic excitation from the lateral thalamus. Same symbols as in Figure 14.

(ACh) on the cat's thalamic relay cells consist of a rapid nicotinic excitation associated with increased membrane conductance, followed by a slow muscarinic depolarization associated with an increase in input resistance (McCormick and Prince, 1987; McCormick, 1990). The early nicotinic excitation may be the basis of thalamic PGO waves ( $\mathrm{Hu}$ et al., 1989b), discussed in the following paper, but it cannot account for the long-lasting activation involved in the enduring process of EEG desynchronization and in the prolonged enhancement of synaptic efficacy of thalamocortical cells (Paré et al., 1990). A longer-latency, longer-duration $(2-6 \mathrm{sec})$ depolarization of lateral geniculate relay cells was elicited after the early nicotinic excitation by stimulating the PB area (see figure 11 in Steriade and Deschênes, 1988). Recently, we have observed that PB and LDT stimulation evoked long-lasting depolarization (mean: $20 \mathrm{sec}$ ), associated with a large increase in input resistance (40-65\%), in a variety of thalamocortical neurons, including those of anterior nuclei; this depolarization was simultaneous with a long-lasting EEG desynchronization (Curró Dossi et al., 1990). In addition to the direct cholinergic excitation from the mesopontine cholinergic nuclei, thalamocortical cells (other than those in anterior nuclei which do not receive reticular thalamic inputs) undergo a process of disinhibition consequent to the powerful hyperpolarization of reticular thalamic neurons elicited by $\mathrm{ACh}$ application in vitro (McCormick and Prince, 1986) or by stimulation of the $\mathrm{PB}$ area in vivo (Hu et al., 1989a).

Thus, mesopontine cholincrgic ncurons are good candidates for (1) disrupting the synchronized spindle oscillations in thalamocortical systems upon arousal and REM sleep, through the inhibition of the spindle generator, the GABAergic reticular thalamic nucleus (Steriade et al., 1985, 1987); and (2) directly activating as well as disinhibiting thalamocortical neurons, with consequent depolarization of cortical targets in circumscribed or diffuse cortical territories, as a function of different types of projections arising in various thalamic nuclei.

The PB/LDT cholinergic nuclei are probably the best candidates for an activating structure for tonic and phasic events during both EEG-desynchronized states of $\mathrm{W}$ and REM sleep. They are not, however, the only system involved in such actions. Several notions should be underlined in this respect.

1. Although noradrenergic neurons of locus coeruleus depolarize thalamocortical cells (McCormick and Prince, 1988), con- 


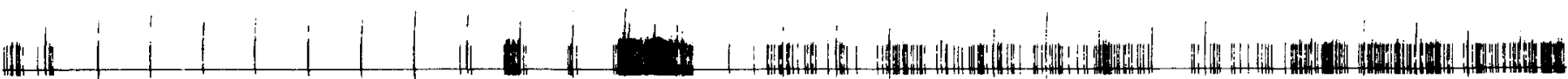

\section{PB unit}
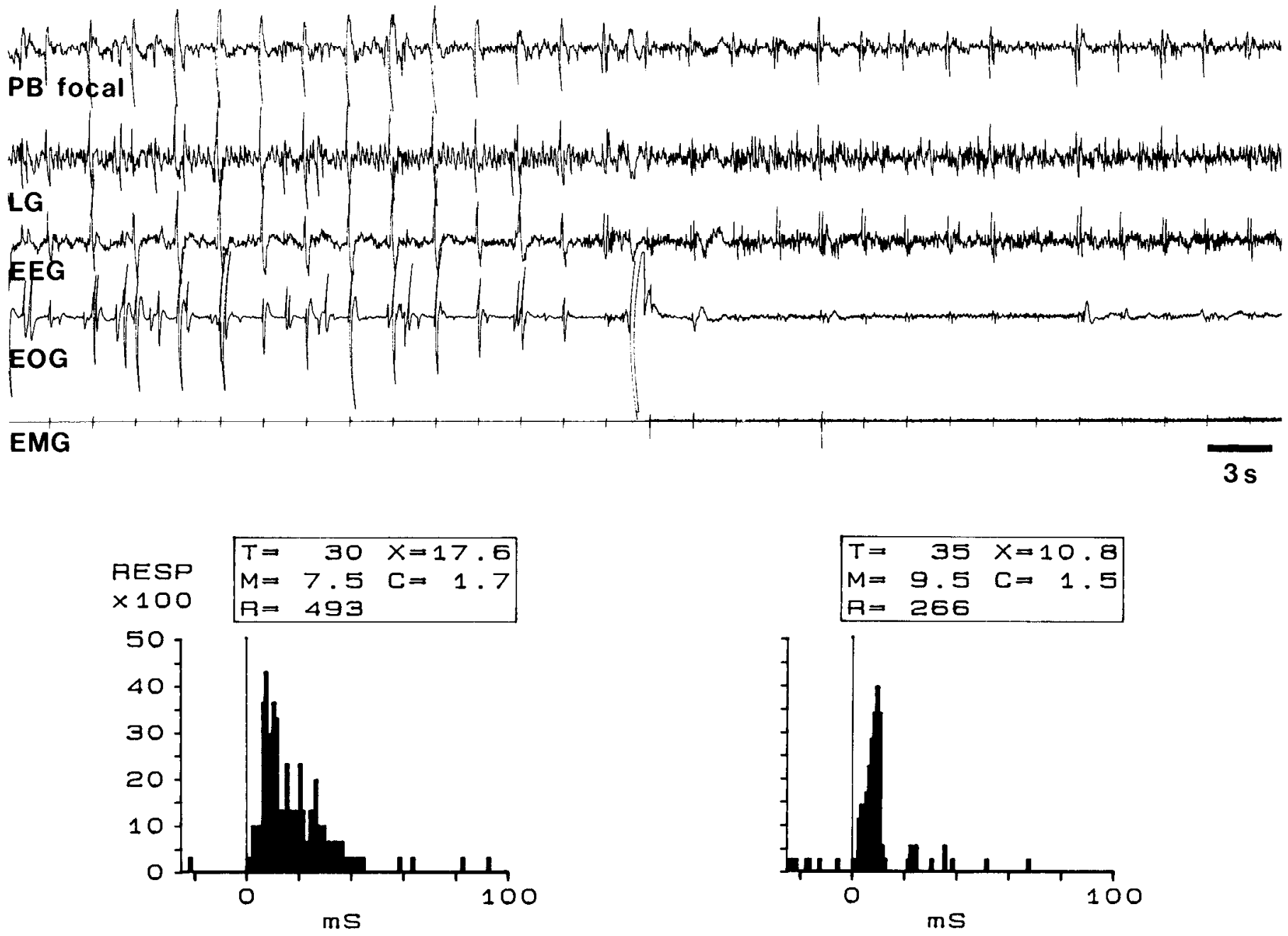

Figure 16. Differential changes in spontaneous firing and synaptic excitability of a PB neuron driven from the rostral intralaminar thalamus during REM sleep and W. Mean firing rates in REM sleep and W: 9.6 and $13 \mathrm{~Hz}$, respectively. Symbols in peristimulus histograms as in preceding figures.

jointly with mesopontine cholinergic neurons, data presented here indicate that $\mathrm{PB} / \mathrm{LDT}$ cells are very active during both $\mathrm{W}$ and REM sleep, whereas previous studies have demonstrated that locus coeruleus neurons are active only during $\mathrm{W}$ and cease firing during REM sleep (see above). Thus, the idea of a synergic activating action of cholinergic and noradrenergic neurons upon the thalamus is conceivable during $\mathrm{W}$, but not during REM sleep, when only the cholinergic contingent is available. The excitatory actions of iontophoretically applied cholinergic agonists upon thalamic neurons are state-dependent: they are present only during EEG desynchronization in acutc prcparations (MacLeod et al., 1984) or during both $\mathrm{W}$ and REM sleep, but not in S, in freely moving animals (Marks and Roffwarg, 1989).

2. The desynchronization of EEG activity, also termed EEG activation because of the simultaneous increase in thalamic and cortical responsiveness (see Steriade et al., 1990a), consists of at least 2 major components: the disruption of spindle oscillations that takes place in the thalamus and the blockade of highamplitude slow $(0.5-4 \mathrm{~Hz})$ or delta waves. As yet, the precise origin of the latter waves is not elucidated. The cortical origin is most often suggested. In the cerebral cortex, delta waves probably originate from synaptic inhibitory processes, but especially from the exceedingly long-lasting calcium-dependent potassium currents (see Steriade and Buzsaki, 1990). Their disruption can be realized by a series of transmitters used by neuronal systems with direct access to the cerebral cortex: basal forebrain cholinergic neurons, ventrolateral posterior hypothalamic histaminergic neurons, and locus coeruleus noradrenergic neurons. The suppressing action of these transmitters upon calcium-dependent potassium currents are now established (Reiner and McGeer, 1987; McCormick and Williamson, 1989). The blockade of delta waves can then contribute to full responsiveness of cortical neurons during EEG-desynchronized behavioral states. Note, however, that EEG activation does not exclusively consist of "negative" events, such as the disruption of synchronized spindles and delta waves. Fast $(40-45 \mathrm{~Hz})$ waves and/or multiunit aclivities have been detected in different cortical areas during highvigilance states (Bouyer et al., 1987) or have been evoked by 
optimal visual stimuli (Gray and Singer, 1989). In vitro the underlying event of sustained subthreshold cortical oscillations at $38-45 \mathrm{~Hz}$ appears to be a voltage-dependent sodium conductance (Llinás and Grace, 1989). In keeping with the idea that this fast rhythm is part of the complex picture of EEG activation, we have recently evoked $40 \mathrm{~Hz}$ cortical oscillations by stimulating PB and LDT cholinergic nuclei after excitotoxic lesions of basal forebrain perikarya (Curro Dossi et al., 1990). Our results indicated that the $40 \mathrm{~Hz}$ rhythm was induced via the brain-stem cholinergic projections driving thalamocortical neurons, as it was abolished by muscarinic blockers.

3 . The existence of multiple systems involved in various components of EEG desynchronization (disruption of spindles or delta waves) and the fact that brain-stem reticular territories with still unidentified transmittcrs (c.g., the rostral midbrain core) also activate thalamocortical neurons together explain the failure that we and others have experienced in attempting to completely disrupt EEG desynchronization for long periods of time. Excitotoxic lesions of the rostral midbrain reticular formation have been followed by a period of 2-4 $d$ of significantly increased $\mathrm{S}$ at the expense of $\mathrm{W}$, associated with continuous EEG synchronization and the replacement of tonic desynchronizing reactions by phasic, quite short-lasting ones (Steriade, 1983). After the same type of lesions in the mesopontine tegmentum, with a mean loss of ChAT-immunoreactive cells of $60 \%$, the animals behaved in a grossly normal manner during $\dot{W}$ and EEG desynchronization was not disrupted in $\mathrm{W}$ or REM sleep (Webster and Jones, 1988). These results may be due to the compensatory function of structures left intact. Even if combined lesions of 2 separate activating structures fail to disrupt the gross $\mathrm{W}$ bchavior and associated EEG desynchronization, the recovery would be attributable to other of the multiple systems involved in this function. For example, the recently reported lack of $\mathrm{W}$ alteration after cellular lesions in both rostral midbrain core and posterior hypothalamus of cat (Denoyer et al., 1989) is explained by the fact that those lesions extended from stereotaxic levels A2 to A6, and the largest part of mesopontine cholinergic neurons (from A1 to P3) was left intact. It is worth mentioning in the context of compensatory functions of intact systems that, after the few days during which $W$ and EEG desynchronization were abolished after the excitotoxic lesion of the rostral midbrain core, a period of increased $\mathrm{W}$ followed, suggesting a denervation supersensitivity of forebrain structures receiving inputs from other activating systems (Steriade, 1983).

These considerations lead us to emphasize the notion of distributed systems when attempting to reveal the substrates of global functions, such as EEG desynchronization and $\mathrm{W}$. We have 2 final remarks concerning these 2 terms, generally employed quite loosely. First, when investigating changes in EEG desynchronization after lesion of one or another activating systems, one should realize that (1) there are at least 2 types of synchronized waves (spindles and delta waves); (2) these waves have distinct sites of origin (thalamus and cortex); (3) different ascending modulatory systems using different neurotransmitters have prevalent access to the thalamus or cerebral cortex; and (4) synchronization or desynchronization cannot be estimated without separate analyses of the power spectra of various EEG rhythms. Second, when using the term W, we must be aware that the behavioral $W$ repertoire of animals used to study neuronal activities across the wake-sleep cycle is very poor, to say the least. This refers not only to head-restrained animals, but also to animals investigated in "freely moving" conditions. Indeed, we examine gross electrographic events, taken as characteristic of $\mathrm{W}$, but leave aside the complex reality of this heterogenous state. Only after submitting the animals to various tasks of attentive behavior and testing their responsiveness to different stimuli, including processes of sculpluring inhibition that are necessary for a finely tuned brain, could we conclude that one or another ascending activating system is not indispensable, because its lesion did not disrupt the $\mathrm{W}$ behavior. The dissection of the $\mathrm{W}$ state by means of attentive tasks is a matter of future investigations of neuronal activities in several ascending activating systems.

\section{References}

Ahlsén G (1984) Brain stem neurones with differential projections to functional subregions of the dorsal lateral geniculate complex in the cat. Neuroscience 12:817-838.

Aston-Jones G, Bloom FE (1981) Activity of norepinephrine-containing locus coeruleus neurons in behaving rats anticipates fluctuations in the sleep-waking cycle. J Neurosci 1:876-886.

Bouyer JJ, Montaron MF, Vahnée JM, Albert MP, Rougeul A (1987) Anatomical localization of cortical beta rhythms in cat. Neuroscience 22:863-869.

Buzsaki G, Bickford RG, Ponomareff G, Thal LJ, Mandel R, Gage FH (1988) Nucleus basalis and thalamic control of neocortical activity in the freely moving rat. J Neurosci 8:4007-4026.

Curró Dossi R, Paré D, Steriade M (1990) Nicotinic and muscarinic depolarizing responses of thalamocortical cells to stimulation of brainstem cholinergic nuclei. Soc Neurosci Abstr 16 (in press).

Denoyer M, Buda C, Jouvet M (1989) La destruction des périkaryas de la formation réticulée mésencéphalique et de l'hypothalamus postérieur n'entraîne pas de troubles majeurs de l'éveil chez le chat. CR Acad Sci Paris 309:265-274.

El Mansari M, Sakai K, Jouvet M (1989) Unitary characteristics of presumptive cholinergic tegmental neurons during the sleep-waking cycle in freely moving cats. Exp Brain Res 76:519-529.

Glenn LL, Steriade M (1982) Discharge rate and excitability of cortically projecting intralaminar thalamic neurons during waking and sleep states. J Neurosci 2:1387-1404.

Gray CM, König P, Engel AK, Singer W (1989) Oscillatory responses in cat visual cortex exhibit inter-columnar synchronization which reflects global stimulus properties. Nature 338:324-337.

Hallanger AE, Levey AI, Lee HJ, Rye DB, Wainer BH (1987) The origins of cholinergic and other subcortical afferents to the thalamus in the rat. J Comp Neurol 262:105-124.

Higo S, Ito K, Fuchs D, Rye D, Wainer B, McCarley RW (1989) Topography of pedunculopontine tegmental nucleus (PPT) interconnections with the lateral geniculate nucleus (LGN) and $n$. prepositus hypoglossi (PH) in the cat. Soc Neurosci Abstr 15:409.

Hobson JA, McCarley RW, Wyzinski PW (1975) Sleep cycle oscillation: reciprocal discharge in two brain stem neuronal groups. Science 189:55-58.

Hu B, Steriade M, Deschênes M (1989a) The effects of brainstem peribrachial stimulation on perigeniculate neurons: the blockage of spindle waves. Neuroscience 31:1-12.

Hu B, Steriade M, Deschênes M (1989b) The cellular mechanisms of thalamic ponto-geniculo-occipital (PGO) waves. Neuroscience 31:2535.

Ito K, McCarley RW (1987) Physiological studies of brainstem reticular connectivity. I. Responses of mPRF neurons to stimulation of bulbar reticular formation. Brain Res 409:97-110.

Jones BE, Cuello AC (1989) Afferents to the basal forebrain cholinergic cell area from pontomesencephalic-catecholamine, serotonin, and acetylcholine-neurons. Neuroscience 31:37-61.

Jones BE, Webster HH (1988) Neurotoxic lesions of the dorsolateral pontomesencephalic tegmentum-cholinergic cell area in the cat. I. Effects upon the cholinergic innervation of the brain. Brain Res 451: 13-32.

Kang Y, Kitai ST (1990) Electrophysiological properties of pedunculopontine neurons and their postsynaptic responses following stimulation of substantia nigra reticulata. Brain Res (in press).

Khateb A, Serafin M, Muhlethaler M (1989) Midbrain reticular neu- 
rones in vitro are sensitive to amines and opiates. Soc Neurosci Abstr 15:451.

Leonard CS, Llinás R (1987) Low-threshold calcium conductance in parabrachial reticular neurons studied in vitro and its blockade by octanol. Soc Neurosci Abstr 13:1012.

Leonard CS, Llinás RR (1990) Electrophysiology of mammalian pedunculopontine and laterodorsal tegmental neurons in vitro: implications for the control of REM sleep. In: Brain cholinergic systems (Steriade M, Biesold D, eds), pp 205-223. New York: Oxford UP.

Livingstone MS, Hubel DH (1981) Effects of sleep and arousal on the processing of visual information in the cat. Nature 291:554-561.

Llinás R, Grace AA (1989) Intrinsic $40 \mathrm{~Hz}$ oscillatory properties of layer IV neurons in guinea pig cerebral cortex in vitro. Soc Neurosci Abstr 15:660.

Lydic R, McCarley RW, Hobson JA (1983) The time course of dorsal raphe discharge, PGO waves, and muscle tone averaged across multiple sleep cycles. Brain Res 274:365-370.

MacLeod NK, James TA, Starr MS (1984) Muscarinic action of acetylcholine in the rat ventromedial thalamic nucleus. Exp Brain Res 55:553-561.

Marks GA, Roffwarg HP (1989) The cholinergic influence upon rat dorsal lateral geniculate nucleus is dependent on state of arousal. Brain Res 494:294-306.

McCarley RW, Ito K, Rodrigo-Angulo ML (1987) Physiological studies of brainstem reticular connectivity. II. Responses of mPRF neurons to stimulation of mesencephalic and contralateral pontine reticular formation. Brain Res 409:111-127.

McCormick DA (1990) Cellular mechanisms of cholinergic control of neocortical and thalamic neuronal excitability. In: Brain cholinergic systems (Steriade M, Biesold D, eds), pp 236-264. New York: Oxford UP.

McCormick DA, Prince DA (1986) Acetylcholine induces burst firing in thalamic reticular neurones by activating a potassium conductance. Nature 319:402-405.

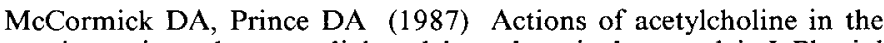
guinea pig and cat medial and lateral geniculate nuclei. J Physiol (Lond) 392:147-165.

McCormick DA, Prince DA (1988) Noradrenergic modulation of firing pattern in guinea pig and cat thalamic neurons in vitro. J Neurophysiol 59:978-996.

McCormick DA, Williamson A (1989) Convergence and divergence of neurotransmitter action in human cerebral cortex. Proc Natl Acad Sci USA 86:8098-8102.

McGinty DG, Harper RW (1976) Dorsal raphe neurons: depression of firing during sleep in cats. Brain Res 101:569-575.

Mesulam MM, Mufson EJ, Wainer BH, Levey AI (1983) Central cholinergic pathways in the rat: an overview based on an alternative nomenclature (Ch1-Ch6). Neuroscience 10:1 185-1201.

Moruzzi G (1972) The sleep-waking cycle. Ergeb Physiol 64:1-165.

Paré D, Smith Y, Parent A, Steriade M (1988) Projections of upper brainstem cholinergic and non-cholinergic neurons of cat to intralaminar and reticular thalamic nuclei. Neuroscience 25:69-88.

Paré D, Steriade M, Deschênes M, Bouhassira D (1990) Prolonged enhancement of anterior thalamic synaptic responsiveness by stimulation of a brain stem cholinergic group. J Neurosci 10:20-33.

Parent A, Steriade M (1981) Afferents from the periaqueductal gray, medial hypothalamus and medial thalamus to the midbrain reticular core. Brain Res Bull 7:411-418.

Parent A, Steriade M (1984) Midbrain tegmental projections of nucleus reticularis thalami of cat and monkey: a retrograde transport and antidromic invasion study. J Comp Neurol 229:548-558.

Reiner PB, McGeer EG (1987) Electrophysiological properties of cortically projecting histamine neurons of the rat hypothalamus. Neurosci Lett 73:43-47.

Ropert N, Steriade M (1981) Input-output organization of midbrain reticular core. J Neurophysiol 46:17-31.

Smith Y, Paré D, Deschênes M, Parent A, Steriade M (1988) Cholinergic and non-cholinergic projections from the upper brainstem core to the visual thalamus in the cat. Exp Brain Res 70:166-180.
Steriade M (1983) Cellular mechanisms of wakefulness and sleep. In: Sleep mechanisms and functions in humans and animals: an evolutionary perspective (Mayes A, ed), pp 161-216. Wokingham, UK: Van Nostrand Reinhold.

Steriade M, Buzsaki G (1990) Parallel activation of thalamic and cortical neurons by brainstem and basal forebrain cholinergic systems. In: Brain cholinergic systems (Steriade M, Biesold D, eds), pp 3-62. New York: Oxford UP.

Steriade M, Deschênes M (1988) Intrathalamic and brainstem-thalamic networks involved in resting and alert states. In: Cellular thalamic mechanisms (Bentivoglio M, Spreafico R, eds), pp 36-62. Amsterdam: Elsevier.

Steriade M, Glenn LL (1982) Neocortical and caudate projections of intralaminar thalamic neurons and their synaptic excitation from the midbrain reticular core. J Neurophysiol 48:352-371.

Steriade M, Hobson JA (1976) Neuronal activity during the sleepwaking cycle. Progr Neurobiol 6:155-376.

Steriade M, McCarley RW (1990) Brainstem control of wakefulness and sleep. New York: Plenum.

Steriade M, Deschênes M, Oakson G (1974) Inhibitory processes and interncuronal apparatus in motor cortex during sleep and waking. I. Background firing and responsiveness of pyramidal tract neurons. $J$ Neurophysiol 37:1065-1092.

Steriade M, Oakson G, Ropert N (1982) Firing rates and patterns of midbrain reticular neurons during steady and transitional states of the sleep-waking cycle. Exp Brain Res 46:37-51.

Steriade M, Sakai K, Jouvet M (1984) Bulbo-thalamic neurons related to thalamocortical activation processes during paradoxical sleep. Exp Brain Res 54:463-475.

Steriade M, Deschênes M, Domich L, Mulle C (1985) Abolition of spindle oscillations in thalamic neurons disconnected from the nucleus reticularis thalami. J Neurophysiol 54:1473-1497.

Steriade M, Domich L, Oakson G, Deschênes M (1987) The deafferented reticularis thalami nucleus generates spindle rhythmicity. $J$ Ncurophysiol 57:260-273.

Steriade M, Paré D, Parent A, Smith Y (1988) Projections of cholinergic and non-cholinergic neurons of the brainstem core to relay and associational thalamic nuclei in the cat and macaque monkey. Neuroscience 25:47-67.

Steriade M, Jones EG, Llinás RR (1990a) Thalamic oscillations and signaling. New York: Wiley.

Steriade M, Paré D, Datta S, Oakson G, Curró Dossi, R (1990b) Different cellular types of ponto-geniculo-occipital waves. J Neurosci 10 : 2560-2579.

Trulson ME, Jacobs BL (1979) Raphe unit activity in freely moving cats: correlation with level of behavioral arousal. Brain Res 163:135150.

Uhlrich DJ, Cucchiaro JB, Sherman SM (1988) The projection of individual axons from the parabrachial region of the brain stem to the dorsal lateral geniculate nucleus in the cat. J Neurosci 8:45654575.

Vincent SR, Reiner PB (1987) The immunohistochemical localization of choline acetyltransferase in the cat brain. Brain Res Bull 18:371415.

Vincent SR, Satoh K, Armstrong DM, Fibiger HC (1983) NADPHdiaphorase: a selective histochemical marker for the cholinergic neurons of the pontine reticular formation. Neurosci Lett 43:31-36.

Webster HH, Jones BE (1988) Neurotoxic lesions of the dorsolateral pontomesencephalic tegmentum-cholinergic cell area in the cat. II. Effects upon sleep-waking states. Brain Res 458:285-302.

Wilcox KS, Grant SJ, Burkhart BA, Cristoph GR (1989) In vitro electrophysiology of neurons in the lateral dorsal tegmental nucleus. Brain Res Bull 22:557-560.

Woolf NJ, Butcher LL (1986) Cholinergic systems in the rat brain. III. Projections from the pontomesencephalic tegmentum to the thalamus, tectum, basal ganglia and basal forebrain. Brain Res Bull 16: 603-637. 